\title{
DIFFUSION AND HIGH TEMPERATURE \\ OXIDATION OF Ni-AI BASED \\ COMPOSITE COATINGS
}

Final Report: DOE Contract \#DE-FG26-98FT40118

by

Donald Susan ${ }^{1}$ and Arnold R. Marder ${ }^{2}$

1. Sandia National Laboratories, Materials Characterization Department, Albuquerque, NM 87185

2. Lehigh University, Department of Materials Science and Engineering, Bethlehem, PA 18015 


\section{TABLE OF CONTENTS}

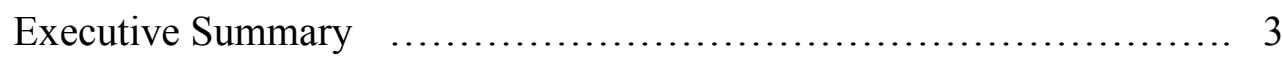

Introduction/List of Publications $\quad$................................ 4

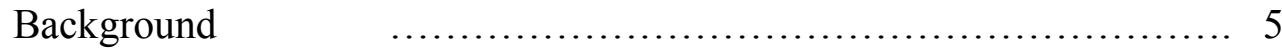

Reaction Synthesis of Ni-Al Based

Particle Composite Coatings ….............................. 6

Diffusion Analysis and

Coating Lifetime Estimation (Abstract) $\quad$..................... 47

Oxidation of Ni-Al Based Electrodeposited Composite Coatings

I: Oxidation Kinetics and Morphology at 800C (Abstract) $\quad \ldots \ldots . .48$

Oxidation of Ni-Al Based Electrodeposited Composite Coatings

II: Oxidation Kinetics and Morphology at 1000C (Abstract)....... 49 


\section{EXECUTIVE SUMMARY}

The diffusion and oxidation behavior of electrodeposited composite coatings were studied using thermogravimetric analysis, electron probe microanalysis, and microstructural characterization techniques. Deposition of Al and Al-Si particles into a Ni matrix produced binary and ternary composite coatings with a uniform particle distribution. During heat treatment, coating morphological development was found to occur by the exothermic reaction $\mathrm{Ni}$ $+\mathrm{Al} \rightarrow \mathrm{NiAl}$ followed by interdiffusion to form a final $\gamma+\gamma^{\prime}$ microstructure. During oxidation at $800^{\circ} \mathrm{C}$, the $\gamma+\gamma^{\prime}$ coatings formed a $\gamma-\mathrm{Al}_{2} \mathrm{O}_{3}$ layer below an outer $\mathrm{NiO}$ scale. At $1000^{\circ} \mathrm{C}, \theta-$ $\mathrm{Al}_{2} \mathrm{O}_{3}$ needles are formed in the early stages. At later times, an $\alpha-\mathrm{Al}_{2} \mathrm{O}_{3}$ layer is found below an outer spinel $\mathrm{NiAl}_{2} \mathrm{O}_{4}$ scale. At both temperatures, the $\mathrm{Al}_{2} \mathrm{O}_{3}$ layer provides good oxidation resistance during long-term exposure. The coatings were compared to bulk Ni-Al alloys, and a critical Al content of about 6 wt. \% was found, below which internal oxidation attack may occur. During exposure at high temperatures, interdiffusion occurs between the Ni-Al coating and the Ni substrate. The diffusion process was modeled using an analytical solution to Fick's second law. The Al content at the coating surface was monitored using EPMA and the results were in agreement with the predicted values from the diffusion equation. Estimates of coating lifetime were made by combining the diffusion results with knowledge of the effect of Al content on oxidation behavior. The results showed that practical use temperatures for Ni-Al coatings are $700-800^{\circ} \mathrm{C}$. At $1000-1100^{\circ} \mathrm{C}, \mathrm{Al}$ depletion begins after a few hundred hours and predicted coating lifetimes are in the range of a few thousand hours. 


\section{INTRODUCTION}

This report includes pertinent background information on electrodeposited composite coatings, a paper describing $\mathrm{Ni}$-Al composite coating deposition and heat treatment, and abstracts of research on coating diffusion and high temperature oxidation. The detailed results of this work are contained in four publications:

1. D.F. Susan, W.Z. Misiolek, and A.R. Marder, "Reaction Synthesis of Ni-Al Based Particle Composite Coatings", Metallurgical and Materials Transactions A, Vol. 32A, pp. 379-390, Feb. 2001.

2. D.F. Susan and A.R. Marder, "Ni-Al Composite Coatings: Diffusion Analysis and Coating Lifetime Estimation", Acta Materialia, Vol. 49, pp. 1153-1163, 2001.

3. D.F. Susan and A.R. Marder, "Oxidation of Ni-Al Based Electrodeposited Composite Coatings I: Oxidation Kinetics and Morphology at 800C”, to be published, Oxidation of Metals.

4. D.F. Susan and A.R. Marder, "Oxidation of Ni-Al Based Electrodeposited Composite Coatings II: Oxidation Kinetics and Morphology at 1000C”, to be published, Oxidation of Metals. 


\section{BACKGROUND}

Coatings are often applied to enhance the surface properties of a component while maintaining the mechanical properties and function of the bulk material. Industries including aerospace and power utilities rely on coatings for protection in high temperature, oxidizing environments. Currently, components such as boiler tubes and turbine blades are coated by thermal spray, weld overlay, or diffusion aluminizing/chromizing techniques. These coatings all have drawbacks such as oxide inclusions and porosity in thermal spray and diffusion coatings or possible high residual stress and brittle coating/substrate interfaces in weld overlays that may lead to premature failure. Thus, it is essential for industry to develop better coatings and new deposition techniques for component protection. Composite electrodeposition is an alternative method of applying an oxidation resistant surface layer. The advantages of this process include low deposition temperature, low cost, no heat affected zone, defect-free microstructure, and the ability to coat components with complex geometry. The process involves deposition of a matrix material with the incorporation of small particles such as Al to provide a source of high temperature oxidation protection. After heat treatment of the particulate composite, a uniform alloy layer is produced. In addition, advanced aluminide materials can be produced with this technique. A major driving force for development of this technique is low cost. It is estimated that the capital cost is one to two orders of magnitude less than other coating systems such as thermal spraying and that the unit costs are approximately half those of competing processes (Honey et al. 1986). Unfortunately, few fundamental studies are available in the literature to evaluate the properties of coatings produced using this electrodeposited metal/metal composite (EMMC) method.

Feasibility of the EMMC technique for depositing nickel aluminide $\left(\mathrm{Ni}_{3} \mathrm{Al}\right)$ coatings was shown in previous work (Susan 1995, Susan et al. 1997). Bulk nickel-aluminide materials based on $\mathrm{Ni}_{3} \mathrm{Al}$ have shown excellent oxidation resistance at temperatures up to about $900^{\circ} \mathrm{C}$ (Brady et al. 1999). However, as a coating material, $\mathrm{Ni}_{3} \mathrm{Al}$ has not been studied in detail to determine its oxidation resistance and long-term diffusion behavior. Therefore, the objectives of this research are to produce nickel aluminide composite coatings; to characterize their high temperature oxidation behavior, and to study the long-term diffusional stability of the coatings in high temperature, oxidizing environments. 


\title{
REACTION SYNTHESIS OF Ni-AI BASED PARTICLE COMPOSITE COATINGS
}

\author{
D.F. Susan ${ }^{\mathrm{a}}$, W.Z. Misiolek ${ }^{\mathrm{b}}$, and A.R. Marder ${ }^{\mathrm{b}}$ \\ ${ }^{a}$ Sandia National Laboratory, Albuquerque, NM \\ ${ }^{b}$ Materials Science and Engineering Department, \\ Lehigh University, Bethlehem, PA
}

\begin{abstract}
Electrodeposited metal matrix/metal particle composite (EMMC) coatings were produced with a nickel matrix and aluminum particles. By optimizing the process parameters, coatings were deposited with 20 volume percent aluminum particles. Coating morphology and composition were characterized using light optical microscopy (LOM), scanning electron microscopy (SEM), and electron probe microanalysis (EPMA). Differential thermal analysis (DTA) was employed to study reactive phase formation. The effect of heat treatment on coating phase formation was studied in the temperature range 415 to $1000^{\circ} \mathrm{C}$. Long-time exposure at low temperature results in the formation of several intermetallic phases at the Ni matrix/Al particle interfaces and concentrically around the original Al particles. Upon heating to the 500$600^{\circ} \mathrm{C}$ range, the aluminum particles react with the nickel matrix to form $\mathrm{NiAl}$ islands within the Ni matrix. When exposed to higher temperatures $\left(600-1000^{\circ} \mathrm{C}\right)$, diffusional reaction between $\mathrm{NiAl}$ and nickel produces $\left(\gamma^{\prime}\right) \mathrm{Ni}_{3} \mathrm{Al}$. The final equilibrium microstructure consists of blocks of $\left(\gamma^{\prime}\right) \mathrm{Ni}_{3} \mathrm{Al}$ in a $\gamma(\mathrm{Ni})$ solid solution matrix, with small pores also present. Pore formation is explained based on local density changes during intermetallic phase formation and


microstructural development is discussed with reference to reaction synthesis of bulk nickel aluminides.

\section{INTRODUCTION}

The composite electrodeposition technique is widely used to produce composite coatings for applications requiring wear and abrasion resistance. These coatings typically contain hard ceramic particles, such as $\mathrm{Al}_{2} \mathrm{O}_{3}$ or $\mathrm{TiO}_{2}$, in an electrodeposited matrix such as nickel. Another type of composite coating can be produced by codeposition of metallic particles into an electrodeposited matrix to produce electrodeposited metal matrix/metal particle composite (EMMC) coatings. Subsequent heat treatment of these composite coatings produces alloys that may have excellent high temperature oxidation resistance. Elemental or alloy particles are codeposited to produce binary or more complex alloys, respectively. For example, Al particles are added to a nickel matrix to produce binary Ni-Al alloys while Al-Si particles can be used to produce ternary Ni-Al-Si coatings. Several alloy coatings have been produced with the EMMC technique including Ni-Cr [1], several MCrAlY alloys [2,3], Ni-Zr [4], and Ni-Al alloys [5-7].

Nickel-aluminum intermetallic alloys based on $\mathrm{NiAl}$ or $\mathrm{Ni}_{3} \mathrm{Al}$ have shown good resistance to high temperature oxidation [8,9]. Application of nickel aluminides as coatings provides the benefit of corrosion protection while maintaining the mechanical properties of the substrate. Conventional techniques for applying nickel aluminide coatings include thermal spray, weld overlay, and pack cementation (aluminizing) among others. The EMMC technique offers an alternative method for applying nickel aluminide coatings with few defects, good coating/substrate bonding, and low deposition and heat treatment temperatures. Typical coating 
deposition is performed at about $50^{\circ} \mathrm{C}$ and intermetallic formation occurs during heat treatment at temperatures as low as $500-600^{\circ} \mathrm{C}$.

The morphological development of EMMC coatings during heat treatment is similar to that found in synthesis of bulk nickel aluminides by powder metallurgy $[10,11]$. However, in EMMC coatings, only one component is in particulate form (Al) while the other component is present as a surrounding matrix (Ni). In EMMC coatings, the particles are effectively isolated from each other by the surrounding electrodeposited matrix. At elevated temperature, phase formation takes place locally around the individual particles. While the as-deposited coatings are essentially fully dense (unlike bulk powder metallurgy compacts), depending on the particle/matrix system, porosity can develop during interdiffusion and intermetallic formation between the particles and matrix.

In previous work [6], the processing and microstructure of as-deposited $\mathrm{Ni}-\mathrm{Al}$ coatings from a nickel sulfamate bath with 1-4 $\mu \mathrm{m}$ Al particles were discussed. This paper further describes coating processing and examines intermetallic phase development during heat treatment of Ni-Al and Ni-Al-Si coatings. The formation of intermetallic phases and pores in the coatings is discussed with reference to the literature on reaction synthesis of bulk, powder metallurgy nickel aluminides.

\section{EXPERIMENTAL PROCEDURE}

\section{COATING DEPOSITION}

The procedure for depositing coatings from a nickel sulfamate bath was based on the literature [12-14] and previous work [6]. A nickel sulfamate electrolyte was used with the following composition: $400 \mathrm{~g} / 1$ nickel sulfamate $\left(\mathrm{Ni}\left(\mathrm{NH}_{2} \mathrm{SO}_{3}\right)_{2}\right), 30 \mathrm{~g} / \mathrm{l}$ boric acid, $5 \mathrm{~g} / 1$ nickel 
chloride $\left(\mathrm{NiCl}_{2}\right), 0.2 \mathrm{~g} / 1$ sodium laurel sulfate (wetting agent), and $0.1 \mathrm{~g} / 1$ coumarin (levelling agent). All of the bath components were mixed in 1 liter of deionized water in a double-jacketed glass beaker. The bath composition is similar to that of Guglielmi [12] and other commercial plating baths $[13,14]$. The sodium laurel sulfate level was slightly lower than in previous work [6]. It was found that excessive amounts of this surfactant can cause "foaming" of the plating bath when Al particles are added and, therefore, minimum levels of this additive were used.

After the plating bath was prepared, the Al powder was added. The powders are codeposited within the nickel matrix to provide for nickel aluminide formation and oxidation resistance at elevated temperature. Ternary silicon additions may further enhance corrosion resistance and, therefore, Ni-Al-Si coatings were also produced by co-deposition of $\mathrm{Al}-\mathrm{Si}$ particles. The powder, obtained from Valimet Inc., was 99.5 min wt.\% Al for deposition of binary Ni-Al coatings or Al-12 wt.\% Si eutectic particles for deposition of ternary Ni-Al-Si coatings. The Al-Si powder composition was chosen because the eutectic particles are commercially available in atomized form. For each powder composition, two different powder sizes were co-deposited: 1.5 and $3 \mu \mathrm{m}$ avg. diameter $\mathrm{Al}$ powder, 2.5 and $5 \mu \mathrm{m}$ avg. diameter Al12 wt.\%Si powder. Powder additions of $75,150,225,300$, and $400 \mathrm{~g} / 1$ were used in experiments to determine the effect of powder bath loading on the resultant particle content in the coatings.

During deposition, the nickel substrate $(12 \times 12 \times 2 \mathrm{~mm})$ was held vertically in the stirred stream of the electrodeposition bath. The bath was maintained at $50^{\circ} \mathrm{C}$ and $\mathrm{pH} \approx 4.0$. In previous work, it was found that deposition current density of about $4.5 \mathrm{~A} / \mathrm{dm}^{2}$ produced the best results [6] and this current density was applied for all coatings in the present research. Plating time of three hours was found to produce coatings of 100-125 $\mu \mathrm{m}$ thickness. To summarize, Table I shows the major processing parameters for typical coating deposition. Further details of 
the coating deposition procedure are found in Ref. 6. After deposition, the samples were sectioned for metallography and/or used in heat treatment analysis.

Table I. Major processing parameters for a typical Ni-Al EMMC coating.

\begin{tabular}{|c|c|}
\hline Plating Bath & Nickel Sulfamate \\
\hline Particle Loading & $400 \mathrm{~g} / \mathrm{l}$ \\
\hline Temperature & $50^{\circ} \mathrm{C}$ \\
\hline PH & $4.0-4.1$ \\
\hline Current Density & $4.5 \mathrm{~A} / \mathrm{dm}^{2}$ \\
\hline Stirring & $400 \mathrm{RPM}$ \\
\hline Plating Time & 3 hours \\
\hline
\end{tabular}

\section{HEAT TREATMENT AND DIFFERENTIAL THERMAL ANALYSIS}

To investigate nickel aluminide alloy formation, samples were heat treated in quartz tubing that was evacuated to approximately 50 millitorr. Typical annealing conditions were three hours at $825^{\circ} \mathrm{C}$. After annealing, the samples were air cooled and broken out of the quartz tubes. The samples were sectioned and the coatings metallographically prepared.

In addition to heat treatment in quartz tubing, differential thermal analysis (DTA) was also performed to study nickel aluminide formation within the coatings. A Netzsch STA 409 DTA was employed with samples of about $0.5 \mathrm{~g}$ mass. The as-plated Ni-Al coating-substrate assemblies were lightly ground and ultrasonically cleaned in ethanol prior to testing. DTA 
experiments were conducted on $\mathrm{Ni}-\mathrm{Al}$ coating/Ni substrate assemblies with a heating rate of $10^{\circ} \mathrm{C} / \mathrm{min}$ in an argon atmosphere. At the end of a test, samples were cooled at $20^{\circ} \mathrm{C} / \mathrm{min}$.

Differential thermal analysis is a useful technique to identify the temperatures at which reactions occur. It should be noted that the coatings make up only a small portion of a substratecoating assembly. The coatings were about $125 \mu \mathrm{m}$ and the Ni substrates were about two millimeters in thickness. Therefore, the coating comprised only about 20 percent of the coatingsubstrate volume (about $13 \mathrm{~mm}^{3}$ of coating material and $60 \mathrm{~mm}^{3}$ of substrate). Nevertheless, it was possible to observe DTA reaction peaks even from this small volume of reactant. Since most of the sample was comprised of Ni substrate, nickel was chosen as the reference material. Because the samples were comprised of two different materials (coating and substrate), the DTA tests are not traditional experiments used to determine a material's physical properties. The tests were performed only to determine if reactions were occurring and to find the approximate reaction temperature(s). Although the coatings comprise only about 20 volume $\%$ of the overall DTA sample (and the substrate acts as a heat sink for exothermic reactions occuring within the coating), a reproducible reaction peak was obtained during duplicate DTA experiments.

\section{MICROSTRUCTURAL CHARACTERIZATION}

Coating-substrate assemblies were analyzed in the as-plated and heat treated condition with light optical microscopy (LOM). Samples were mounted in cold-setting epoxy and prepared using standard metallographic techniques. Grinding was conducted with successively finer silicon carbide papers from 120 to 600 grit. Polishing steps included $6 \mu \mathrm{m}$ and $1 \mu \mathrm{m}$ diamond pastes, $0.3 \mu \mathrm{m}$ alumina suspension, and $0.05 \mu \mathrm{m}$ colloidal silica. To achieve a suitable polish for photomicroscopy and image analysis, a final polish was performed with a vibratory 
polisher for a few minutes with $0.05 \mu \mathrm{m}$ colloidal silica. Although the aluminum particles could be seen in the as-polished coatings without etching, some samples were also etched with Keller's reagent $\left(1 \mathrm{ml} \mathrm{HF}, 1.5 \mathrm{ml} \mathrm{HCl}, 2.5 \mathrm{ml} \mathrm{HNO}_{3}, 95 \mathrm{ml} \mathrm{H}_{2} \mathrm{O}\right)$ to further outline the particles. In particular, the eutectic structure of the Al-12Si particles was observed with this technique.

In the as-plated condition, coatings were also prepared in planar view (unmounted samples) by polishing down on the coating surface. This was performed to provide a large viewing area for measurement of particle volume fraction. The coating microstructure and particle distribution was found to be the same in the planar and cross-sectional orientations. Quantitative image analysis (QIA) was performed with a LECO 3001 image analysis system at a magnification greater than 1000 times using at least twenty fields of view on each sample. It was assumed that, for spherical particles, the area percent of particles in random planes represents the volume percent of particles in the coating.

Characterization of coatings at higher magnification was achieved with a JEOL 6300F field emission scanning electron microscope (SEM) operated at 2 to $15 \mathrm{kV}$ in both secondary and backscatter (BSE) modes. In general, the epoxy mounted samples were carbon coated prior to analysis to avoid charging effects.

Electron probe microanalysis (EPMA) was performed on a JEOL 733 SuperProbe equipped with wavelength dispersive spectrometry (WDS) to quantitatively identify the composition of phases in the heat treated coatings. The mounted and polished samples were surrounded with carbon tape (no carbon coating) to avoid charging during analysis. Pure element standards were used for analysis of aluminum, nickel, and silicon. The accelerating voltage was $20 \mathrm{kV}$ and the probe current was $14 \mathrm{nA}$. A computerized "phi-rho-z" correction 
program was implemented that is particularly suited for analyzing light elements with high x-ray absorption corrections.

\section{RESULTS}

Several processing parameters are involved in electrodeposition including: bath composition, temperature, $\mathrm{pH}$, stirring speed, and current density among others. Of these, two important variables affecting coating microstructure and properties are bath composition and deposition current density. In previous work [6], it was determined that nickel coatings with low stress and minimal coating defects could be deposited from a sulfamate bath at current density of about 4.5-5 $\mathrm{A} / \mathrm{dm}^{2}$. In composite electrodeposition, a major processing parameter is powder bath loading, which was investigated in this study. Processing variables of secondary importance were powder composition and particle size. The aim of the deposition phase of this research was to determine the effect of $\mathrm{Al}$ particle content in the bath on the resultant particle content incorporated into Ni-Al EMMC coatings. By controlling the processing parameters, coatings with maximized Al content and optimized microstructure were produced. The optimized coatings were then used for heat treatment studies.

\section{MORPHOLOGY OF AS-DEPOSITED COATINGS}

The as-plated coating microstructure contains columnar nickel grains that grow outward from the substrate with grain widths of a few microns $[6,15]$. The addition of Al particles to the Ni matrix reduces the columnar grain size and produces a corresponding increase in as-plated coating microhardness [6]. The nickel matrix microstructure will not be discussed further in this paper but attention will be paid to the Al particle content. A typical LOM photomicrograph of an 
as-plated Ni-Al EMMC coating cross-section is shown in Figure 1. This example is Ni-Al, produced with $150 \mathrm{~g} / \mathrm{l}$ bath loading of $1.5 \mu \mathrm{m}$ nominal sized Al powder. The coating has constant thickness of about $125 \mu \mathrm{m}$, with no cracks or other defects, and good bonding with the substrate. A uniform distribution of $\mathrm{Al}$ particles is found across the coating. Figure 2 contains LOM photomicrographs of $\mathrm{Ni}-\mathrm{Al}$ and $\mathrm{Ni}-\mathrm{Al}-\mathrm{Si}$ composite coatings (planar views). To produce the Ni-Al-Si samples, aluminum-12 wt.\% Si eutectic powders are codeposited into the Ni matrix. Experiments with two particle sizes were performed for each particle composition. As shown in Figure 2, Ni-Al coatings were codeposited with 1.5 and $3 \mu \mathrm{m}$ powders and Ni-Al-Si coatings were codeposited with 2.5 and $5 \mu \mathrm{m}$ particles. In all cases, the powders are approximately spherical in shape and distributed uniformly throughout the coating. The coatings are not etched to show the columnar $\mathrm{Ni}$ grain boundaries (see reference [6]). The Ni-Al-Si coatings were etched with Keller's reagent to display the eutectic microstructure of the Al-12Si powder. 


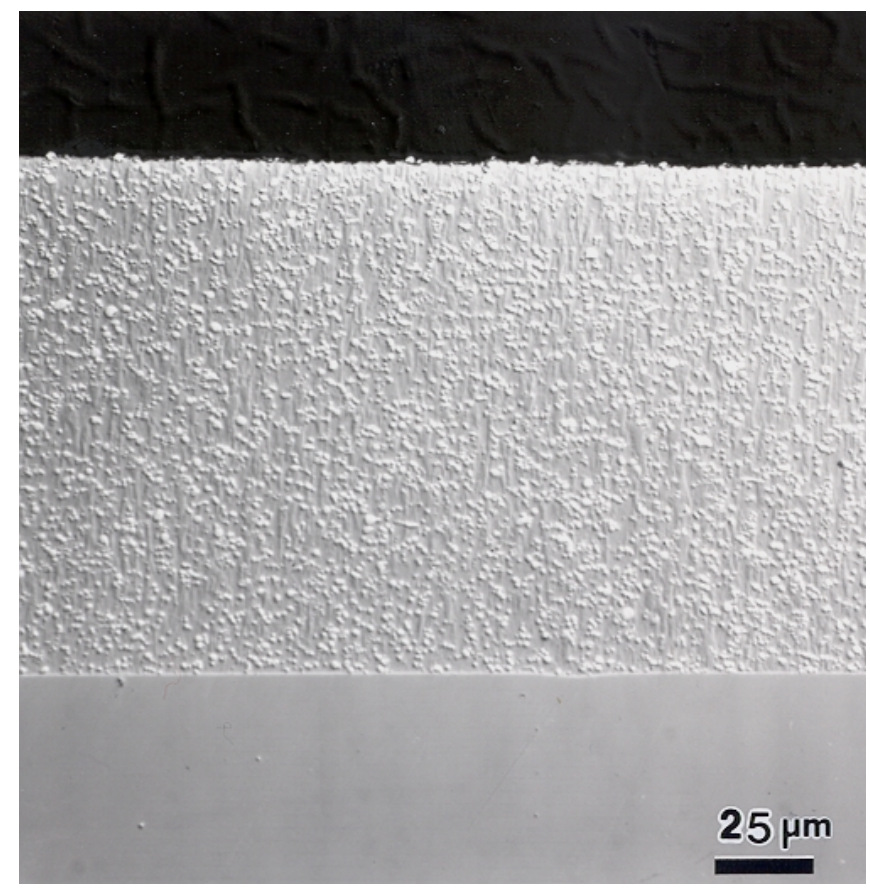

Figure 1. LOM photomicrograph of as-plated Ni-Al coating cross-section (Nomarski DIC). 


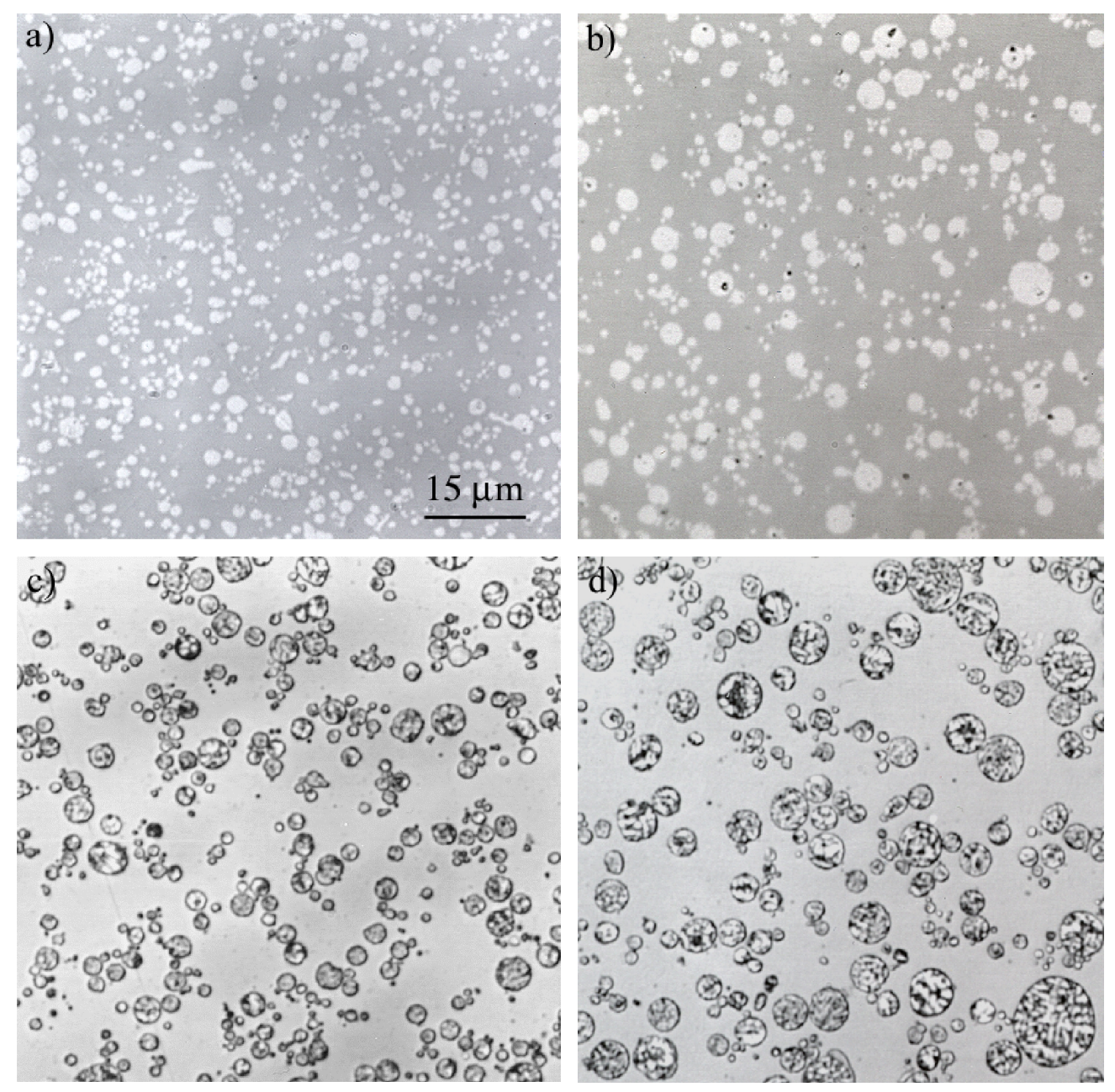

Figure 2. Morphology of Ni-Al and Ni-Al-Si composite coatings. a) Ni-1.5 $\mu \mathrm{m} \mathrm{Al}$, b) Ni-3 $\mu \mathrm{m}$ Al, c) Ni-2.5 $\mu \mathrm{m}$ Al-Si (Keller's etch), d) Ni-5 $\mu \mathrm{m}$ Al-Si (Keller's etch)

\section{PARTICLE CONTENT IN Ni-Al AND Ni-Al-Si COATINGS}

To determine the effect of particle bath loading on the volume fraction of particles in the coatings, deposition experiments were performed with 75, 150, 225, 300, and $400 \mathrm{~g} / \mathrm{l}$ of powder in the bath. The relative volume of particles in the as-plated coatings determines the resultant coating composition and dictates, through the phase diagram, whether aluminide formation is possible. 
Figure 3 illustrates the effect of processing parameters (amount of particles in the bath, particle composition, particle size) on the resultant particle content of the coatings. Figure $3 \mathrm{a}$ shows a plot of particle volume percent in the coating vs. particle bath loading for $\mathrm{Al}$ and $\mathrm{Al}-$ 12Si powders. The average and standard deviation of image analysis results were used to determine the effect of particle bath loading on volume percent particles in the coating. The amount of particles in the coating increases as the bath loading increases. Above about $300 \mathrm{~g} / \mathrm{l}$, the particle content in the coatings levels off. It appears, therefore, that an upper limit has been reached at approximately 20 vol.\% Al (and 30 vol.\% Al-12Si) under these experimental conditions. Coatings deposited with $400 \mathrm{~g} / 1$ particle bath loading were used in the heat treatment and DTA experiments presented below.

The highest bath content of $400 \mathrm{~g} / \mathrm{l}$ corresponds to only $12 \%$ by volume of particles in the bath. As shown in Figure 3b, for a given particle content in the bath, a higher resultant volume percent is found in the coatings. When particles are dispersed in the bath, they develop a positive charge due to a layer of $\mathrm{Ni}^{2+}$ ions on their surface. Bath stirring supplies particles at a constant rate to the substrate surface where they adhere to the negatively charged substrate (cathode). During deposition, a steady state is thereby established in which the coating grows around the particles as new particles and fresh electrolyte are continuously supplied at the cathode surface. However, because of the electrostatic attraction, the steady state particle loading local to the surface is higher than the bulk bath loading. As a result, while the bulk bath loading is only 12 volume percent, the volume fraction of particles trapped within the growing deposit can be significantly higher (Figure $3 b$ ). High coating vol. $\%$ to bath vol. $\%$ ratios are often found for electrodeposited composites. For example, for small $\mathrm{Al}_{2} \mathrm{O}_{3}$ particles in a nickel matrix, coatings with over 30 volume $\%$ particles have been obtained from baths with only $6 \%$ particles 
by volume [7]. In addition, coating particle contents up to several times the average bath volume percent were found for chromium particles [1] and $\mathrm{TiO}_{2}$ particles [12] in a nickel matrix. Within the range chosen for this study, particle size had little effect on codeposited volume percent as shown in Figure 3.

In summary, the results show that the composite electrodeposition technique can be used to successfully produce Ni-Al based composite coatings. The deposition follows the general trend of increasing coating volume percent with increased bath loading, up to approximately 300 g/l. Particle type (Al-12Si vs. pure $\mathrm{Al}$ ) has a larger effect on codeposition than particle size in the 1.5 to $5 \mu \mathrm{m}$ powder size range. 

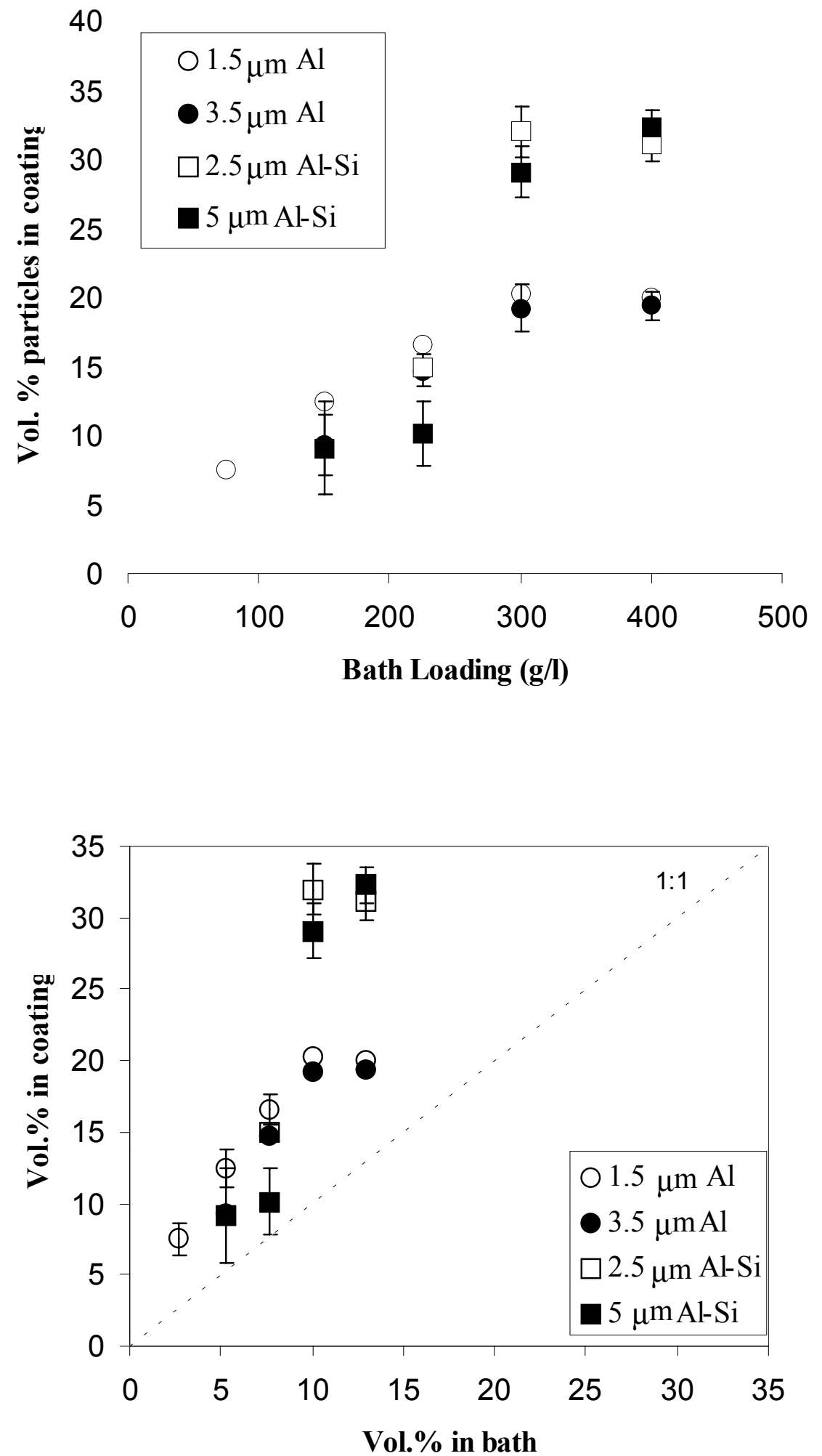
Figure 3a. Effect of bath loading on volume percent for particles of varying size and composition.

Figure 3b. Volume percent particles in coating vs. volume percent particles in bath.

\section{MICROSTRUCTURAL DEVELOPMENT DURING HEAT TREATMENT}

\section{General Heat Treatment Behavior}

When as-plated Ni-Al EMMC coatings are exposed to high temperature, diffusion occurs between the $\mathrm{Al}$ particles and the Ni matrix. The final phases present in a heat treated, 20 volume $\% \mathrm{Al}$ coating depend on temperature and the Ni-Al phase diagram. As an example, a 15 atomic $\% \mathrm{Al}$ (approximately 20 volume $\% \mathrm{Al}$ particles) coating annealed at $800^{\circ} \mathrm{C}$ lies in the two-phase $\gamma+\gamma^{\prime}$ field of the Ni-Al phase diagram (Figure 4). Previous research has shown that exposure at 635,800 , and $1000^{\circ} \mathrm{C}$, for times as short as one hour, produces a two-phase microstructure of $\gamma+$ $\gamma^{\prime}[5,6]$. In addition, small pores are found throughout the coating microstructure. A backscattered electron (BSE) photomicrograph of a Ni-Al sample heat treated at $850^{\circ} \mathrm{C}$ for ten hours is shown in Figure 5a. The light gray and dark gray phases are identified (see EPMA results below) as $\gamma(\mathrm{Ni})$ and $\gamma^{\prime}\left(\mathrm{Ni}_{3} \mathrm{Al}\right)$, respectively. The morphology is similar, therefore, to that found in previous work on Ni-Al EMMC coatings [5]. Small pores appear black in the photomicrographs. However, some of the black regions may contain oxide $\left(\mathrm{Al}_{2} \mathrm{O}_{3}\right)$ formed from the $\mathrm{Al}$ particles during heat treatment, as found by Izaki et al. [5]. The $\gamma+\gamma^{\prime}$ equilibrium microstructure corresponds well with the original Al particle content in the as-plated coatings measured by QIA (Figure 3). The blocky shape of the $\mathrm{Ni}_{3} \mathrm{Al}$ phase in Figure 5a, and comparison to the original Al particles in Figure 1, indicates that more than one Al particle is involved in the 
formation of $\mathrm{Ni}_{3} \mathrm{Al}$, i.e. overlapping diffusion fields occur during heat treatment. A similar $\gamma+\gamma^{\prime}$ microstructure is produced during heat treatment of the ternary Ni-Al-Si coatings as shown in Figure $5 b$.

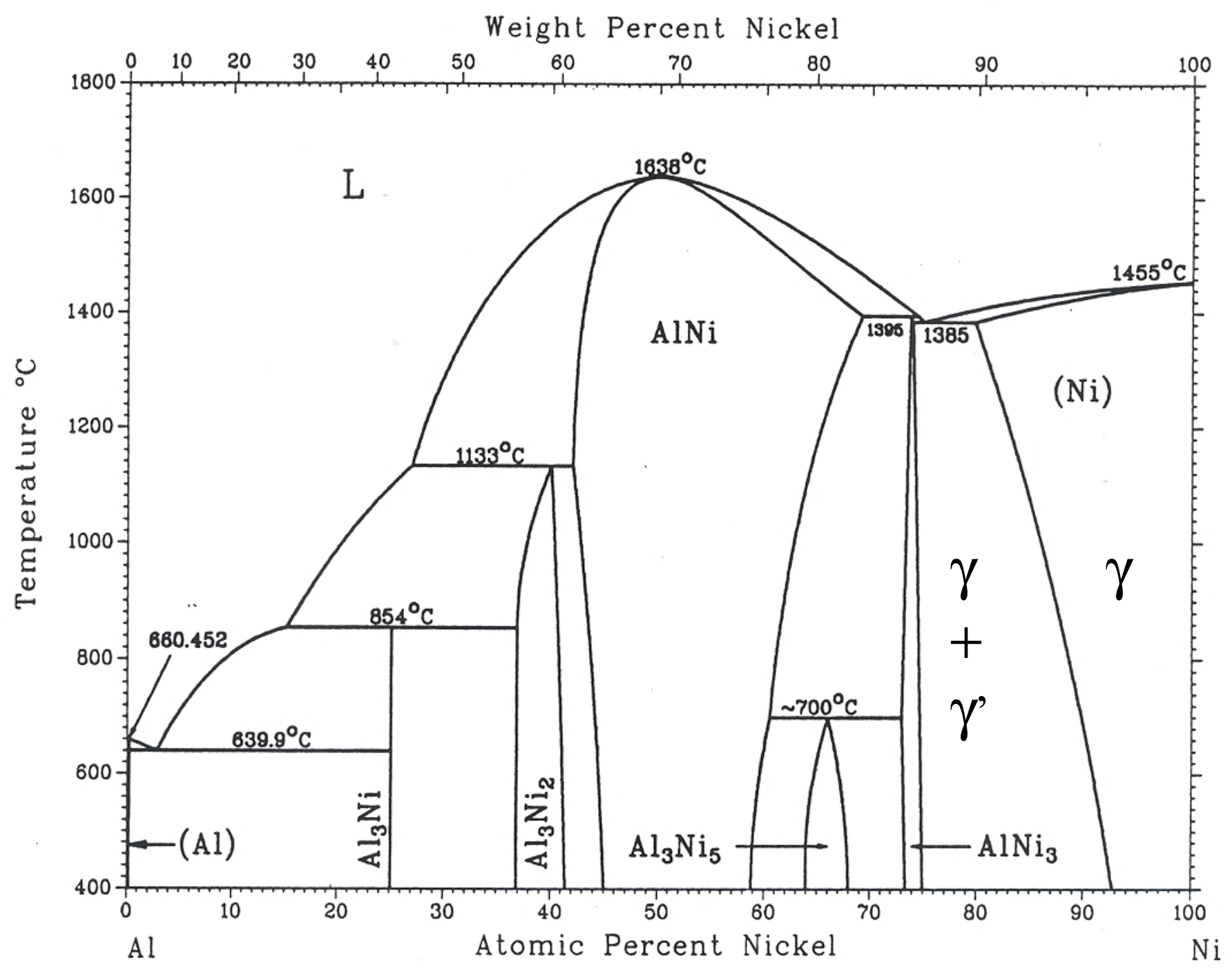

Figure 4. Equilibrium phase diagram for Ni-Al [17]. 

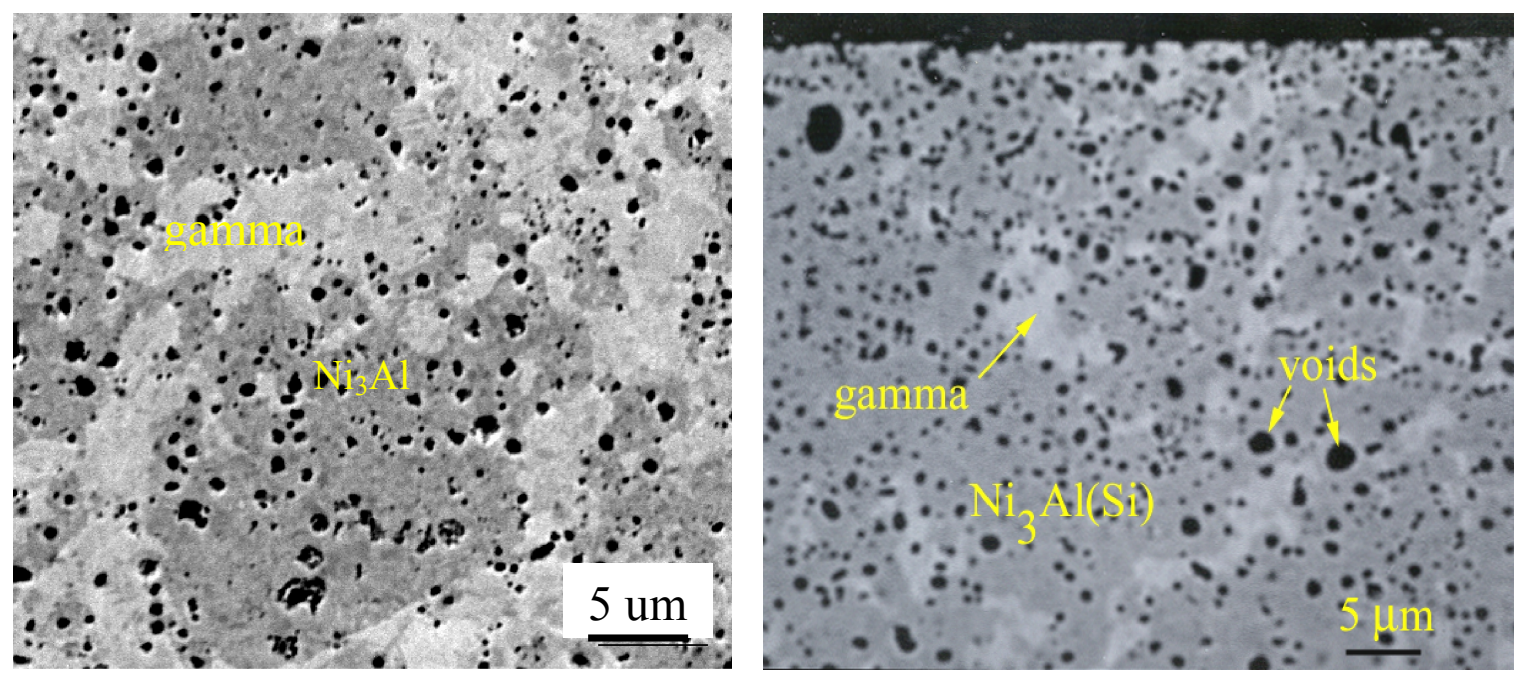

Figure 5. a) BSE photomicrograph of $\mathrm{Ni}-\mathrm{Al}$ sample diffused at $850^{\circ} \mathrm{C}$ for 10 hours and b) $\mathrm{BSE}$ photomicrograph of Ni-Al-Si sample diffused at $800^{\circ} \mathrm{C}$ for 100 hours.

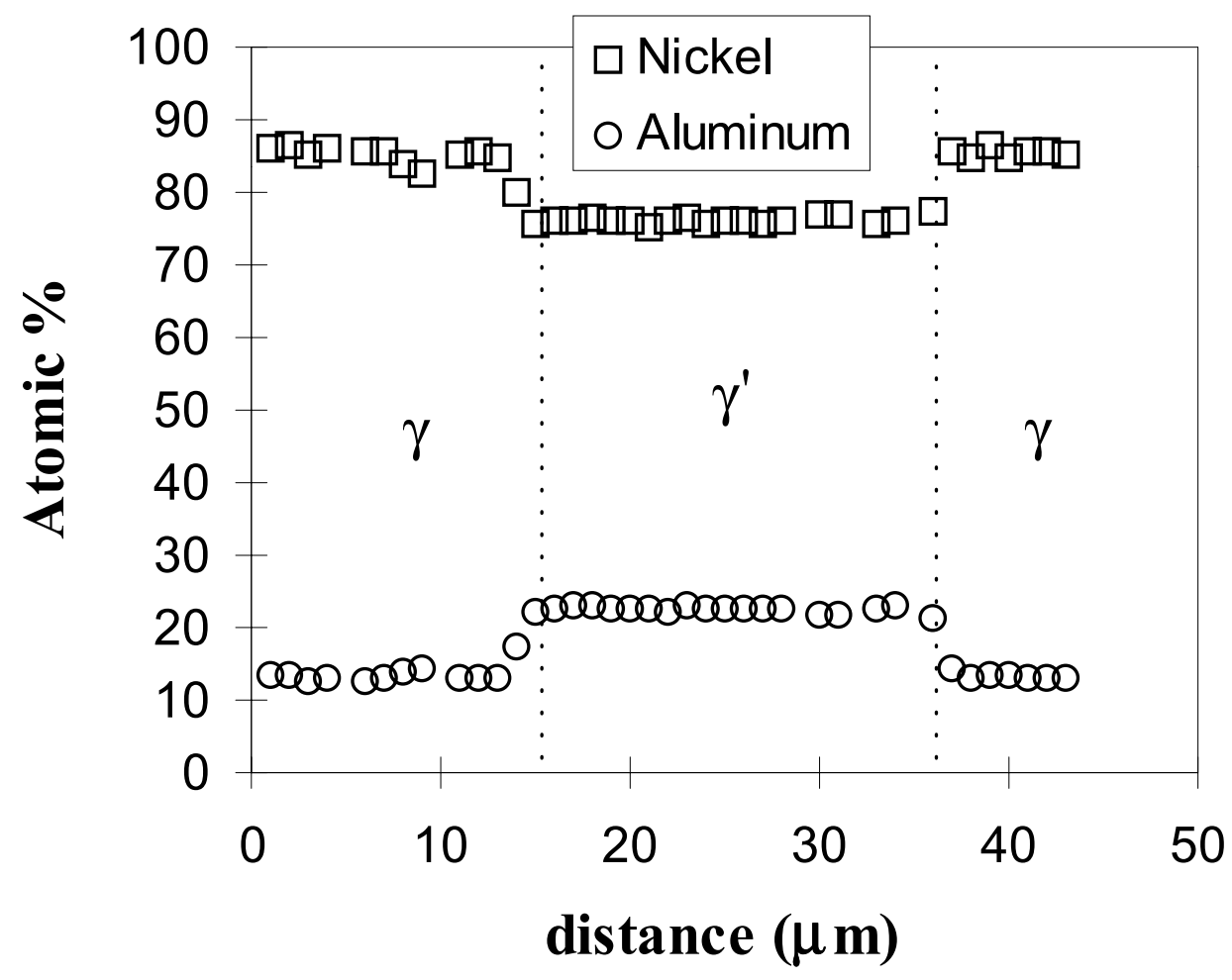

Figure 6. EPMA trace in $\mathrm{Ni}-\mathrm{Al}, 850^{\circ} \mathrm{C}, 10$ hour sample. 
To determine the composition of phases in the heat treated coatings, electron probe microanalysis (EPMA) was performed. Figures 6 and 7 exhibit EPMA results for Ni-Al and NiAl-Si samples annealed for 10 hours at $850^{\circ} \mathrm{C}$ and 100 hours at $800^{\circ} \mathrm{C}$, respectively. For the binary alloy, the compositions of the $\gamma$ and $\gamma^{\prime}$ phases correspond relatively well to the Ni-Al phase diagram (Figure 4) at $850^{\circ} \mathrm{C}$. Furthermore, the precision of the EPMA wavelength dispersive spectrometry (WDS) technique can be seen by examining the results for Ni-Al-Si coatings shown in Figure 7. The trace was performed through the entire coating with varying step sizes. The step size was decreased within large single phase fields to determine the composition of the phase. Step size was also varied to avoid holes in the microstructure. The $\mathrm{Ni}, \mathrm{Al}$ and $\mathrm{Si}$ levels in each phase are labeled in Figure 7. The other data points (between the $\gamma$ and $\gamma^{\prime}$ compositions) correspond to locations on or near a phase boundary. Decomposition of the original Al-12\% Si particles and diffusion of the elemental constituents into the Ni matrix produces an overall Si content in the annealed coatings of about 2 atomic percent. As shown in Figure $7 \mathrm{~b}$, it was possible to measure the difference between the Si content in the $\gamma$ phase (1.6 \pm 0.1 at. $\%)$ and the $\gamma^{\prime}$ phase $(2.5 \pm 0.1$ at. $\%)$. These compositions correspond to the ends of the tie line in the two-phase $\gamma(\mathrm{Ni})+\gamma^{\prime} \mathrm{Ni}_{3} \mathrm{Al}(\mathrm{Si})$ region of the ternary $\mathrm{Ni}-\mathrm{Al}-\mathrm{Si}$ phase diagram displayed in Figure 8. 

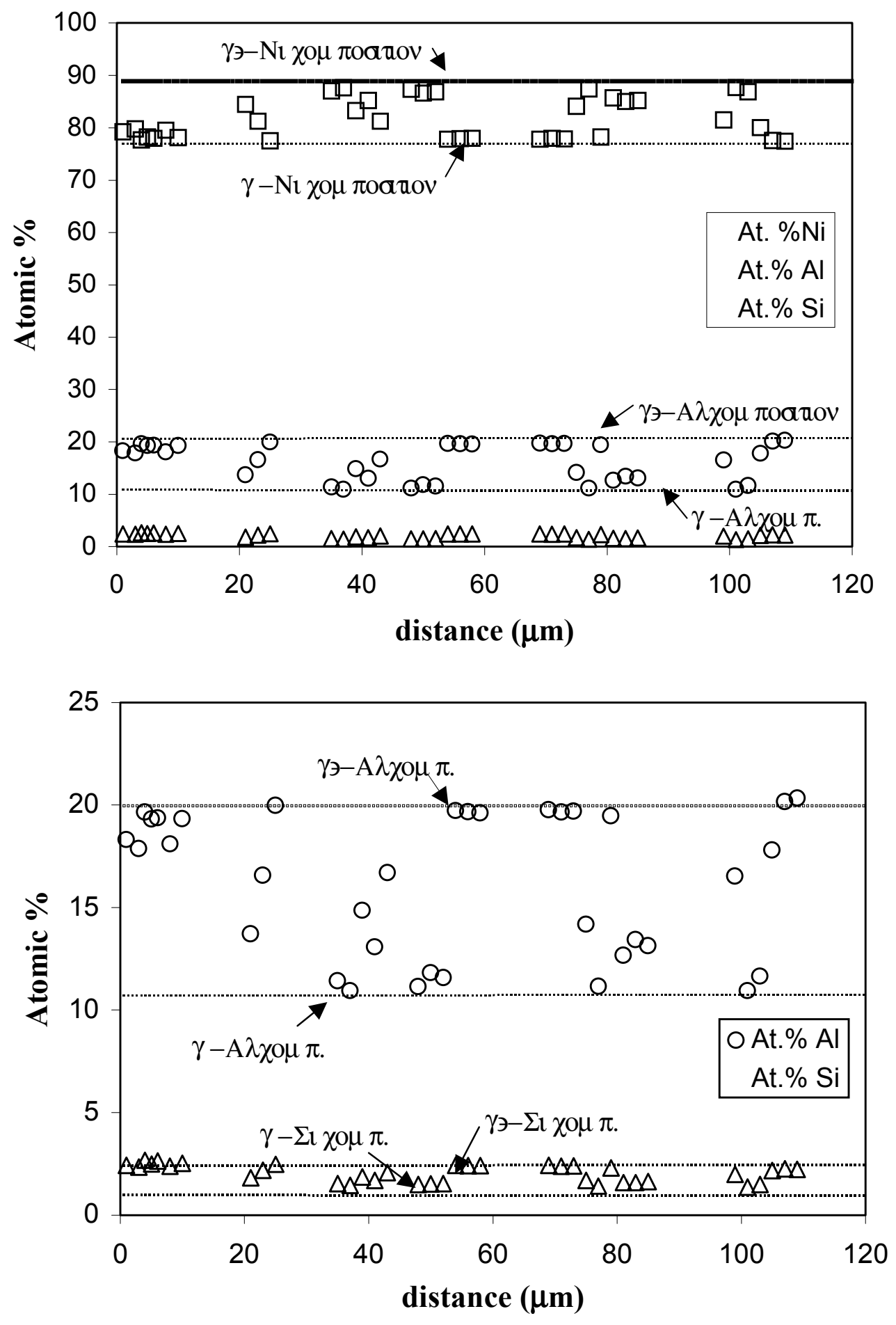
Figure 7. a) EPMA trace in Ni-Al-Si, $800^{\circ} \mathrm{C}, 100$-hour sample. b) Close-up of (a) showing $\mathrm{Si}$ content in the $\gamma$ and $\gamma^{\prime}$ phases.

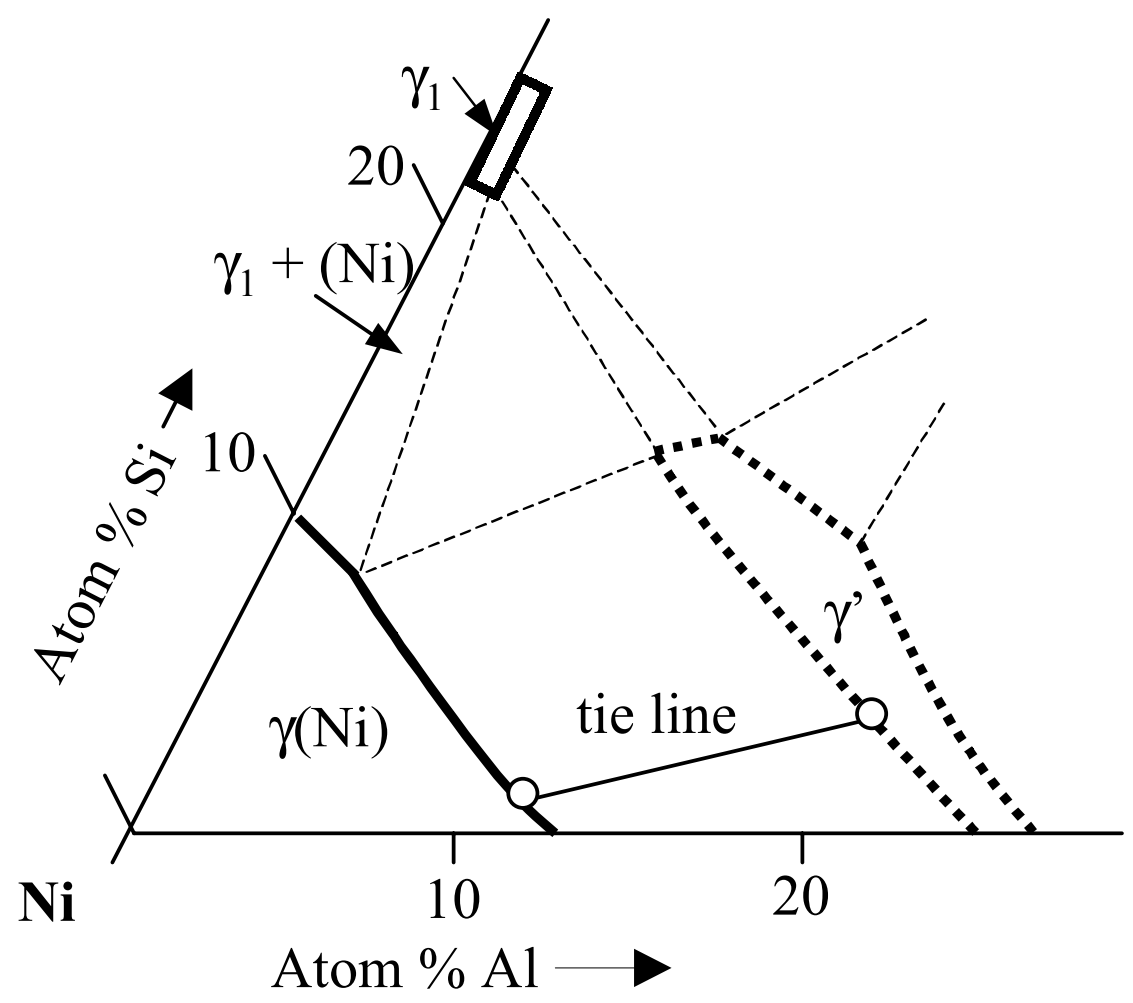

Figure 8. Average composition of $\gamma$ and $\gamma^{\prime}$ shown on Ni-Al-Si phase diagram for $900^{\circ} \mathrm{C}$. (Note the probe measurement data is from $800^{\circ} \mathrm{C}$ heat treatment). 


\section{Differential Thermal Analysis}

Figure 9a displays a typical DTA trace for a $\mathrm{Ni}-\mathrm{Al}(3.5 \mu \mathrm{m}$ diameter $\mathrm{Al}$ powder $)$ coatingsubstrate sample heated from room temperature to $1000^{\circ} \mathrm{C}$. The onset of a single exothermic peak is found at $518^{\circ} \mathrm{C}$ and the reaction is complete at $532^{\circ} \mathrm{C}$ (reaction time is about two minutes). No other peaks are observed up to $1000^{\circ} \mathrm{C}$. To further investigate the exothermic reaction, a test was started and then stopped during the reaction. The DTA trace for this test (which reached $522^{\circ} \mathrm{C}$ ) is shown in Figure $9 \mathrm{~b}$ superimposed on the $1000^{\circ} \mathrm{C}$ sample data. The results show the reproducibility of the reaction peak. To analyze the exothermic reaction, the partially reacted sample microstructures are discussed below. Other samples were also heated in a furnace to various temperatures above and below the reaction peak. The microstructures of these samples are described below.
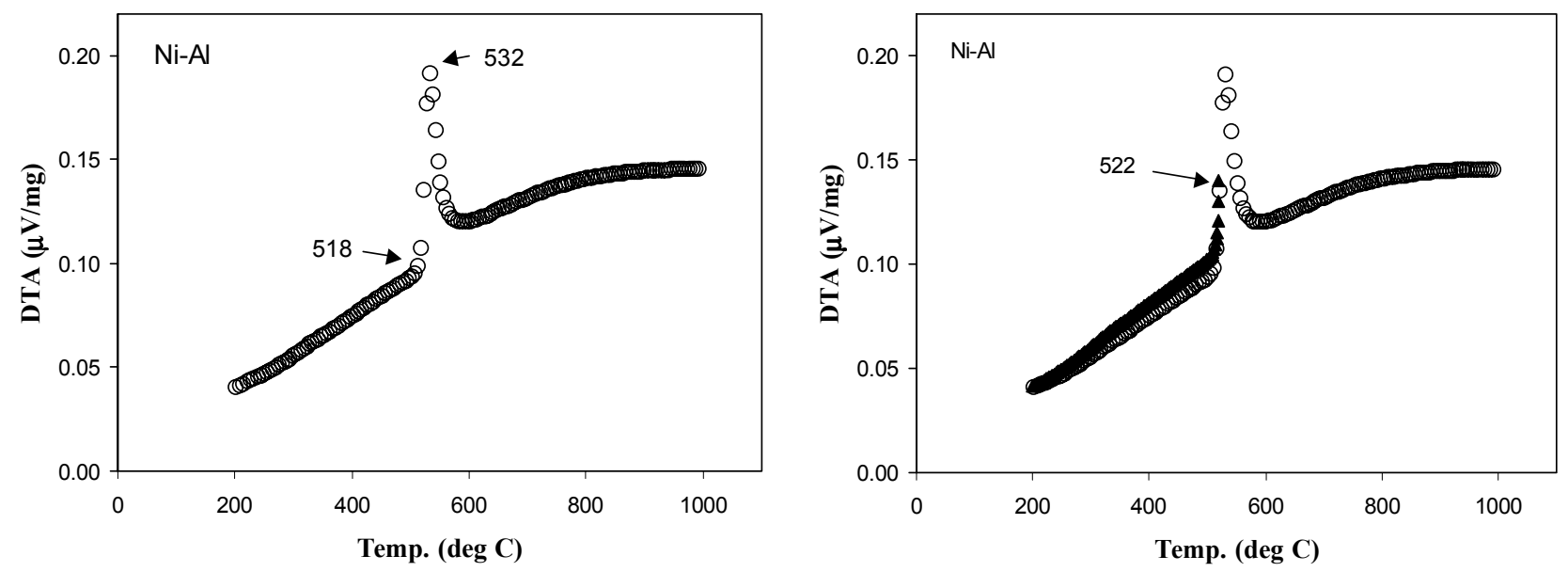

Figure 9. a) DTA trace for Ni-3 $\mu \mathrm{m}$ diam. Al sample heated to $1000^{\circ} \mathrm{C}$. b) DTA trace for Ni-3 $\mu \mathrm{m}$ diam. Al heated to $522^{\circ} \mathrm{C}$ superimposed with data from (a). 


\section{Low Temperature $\left(\sim 400-450^{\circ} \mathrm{C}\right)$ Morphological Development}

Coating samples were heated to $450^{\circ} \mathrm{C}$ (below reaction peak) at $10^{\circ} \mathrm{C} / \mathrm{min}$ and then immediately cooled to room temperature $\left(20^{\circ} \mathrm{C} / \mathrm{min}\right)$. The particles were found to be unreacted (except for spheroidization of the eutectic structure of Al-12Si particles). The spheroidization of the eutectic is expected at $450^{\circ} \mathrm{C}$. This temperature is about $78 \%$ of the $\mathrm{Al}-\mathrm{Si}$ eutectic temperature of $577^{\circ} \mathrm{C}$ [17]. No evidence of intermetallic formation was found with light optical microscopy of these short-time, low-temperature samples.

If the coatings are held isothermally at $>400^{\circ} \mathrm{C}$ for long times, however, the interdiffusion is sufficient for appreciable intermetallic formation to occur. To investigate the diffusional reactions, $\mathrm{Ni}-\mathrm{Al}$ and $\mathrm{Ni}-\mathrm{Al}-\mathrm{Si}$ samples were held in a furnace at $415^{\circ} \mathrm{C}$ (well below the DTA exothermic peak) for 24 hours. Figure 10 contains LOM photomicrographs of the Ni-Al and NiAl-Si coatings. Several phases (numbered in figure) are observed as varying shades of gray in the polished samples. Some unreacted particles remain (white particles) even after long diffusion time. In general, the phases form concentrically, as expected for spherical diffusion couples. Phases also form at the original $\mathrm{Al}$ particle/Ni matrix interfaces. The Ni-Al sample (Figure 10a) contains $\mathrm{Al}$ particles, Ni matrix, and two different intermetallics along with small pores. The Ni-Al-Si sample microstructure (Figure 10b) is very complex with unreacted particles, Ni matrix, and possibly three intermetallic phases. Intermetallic phases are found mainly at the particle/matrix interfaces in the Ni-Al-Si sample.

The $415^{\circ} \mathrm{C}$, 24-hour samples were analyzed at higher magnification with scanning electron microscopy (SEM). Figures 11 and 12 exhibit in more detail the complex, multiphase morphology of the Ni-Al and Ni-Al-Si coatings. In the SEM photomicrographs, the unreacted 
Al particles appear dark (Figure 11a) due to atomic number contrast. (Small, bright particles in these figures are probably due to polishing compound that was trapped inside pores during sample preparation.) Phases bridging two original Al particles are clearly shown in the higher magnification photomicrograph in Figure 11b. This phenomenon is also well-known as neck growth in the PM sintering literature [18]. The Ni-Al-Si microstructure (Figure 12) is complex with several intermetallic phases connecting multiple original particles. Altogether, the morphology at $415^{\circ} \mathrm{C}$ contains several intermetallic phases, as would be expected from the Ni-Al and Ni-Al-Si phase diagrams. The particles and matrix behave as many small diffusion couples with interaction between multiple original Al particles. It is interesting that intermetallic phase formation is not uniform in all directions. It appears that more intermetallic phase formation occurs in regions between more closely spaced particles. 


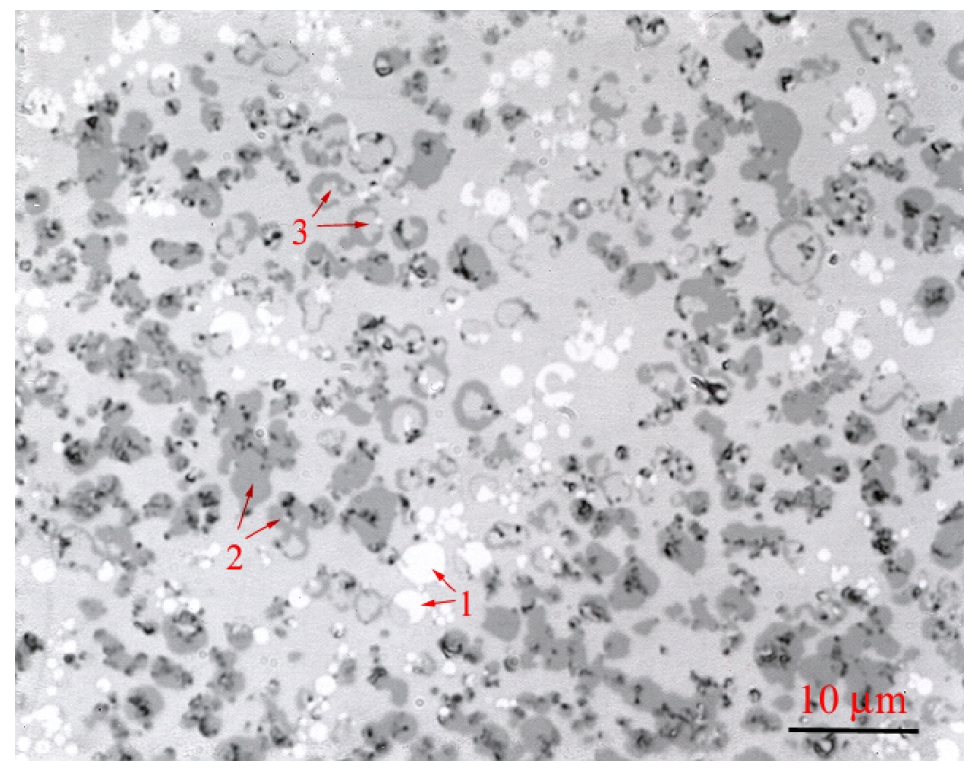

Figure 10a. Morphology of Ni-Al coating held isothermally at $415^{\circ} \mathrm{C}$ for 24 hours. 1 - unreacted Al, 2 - dark gray (NiAl), 3 - Al-rich intermetallic.

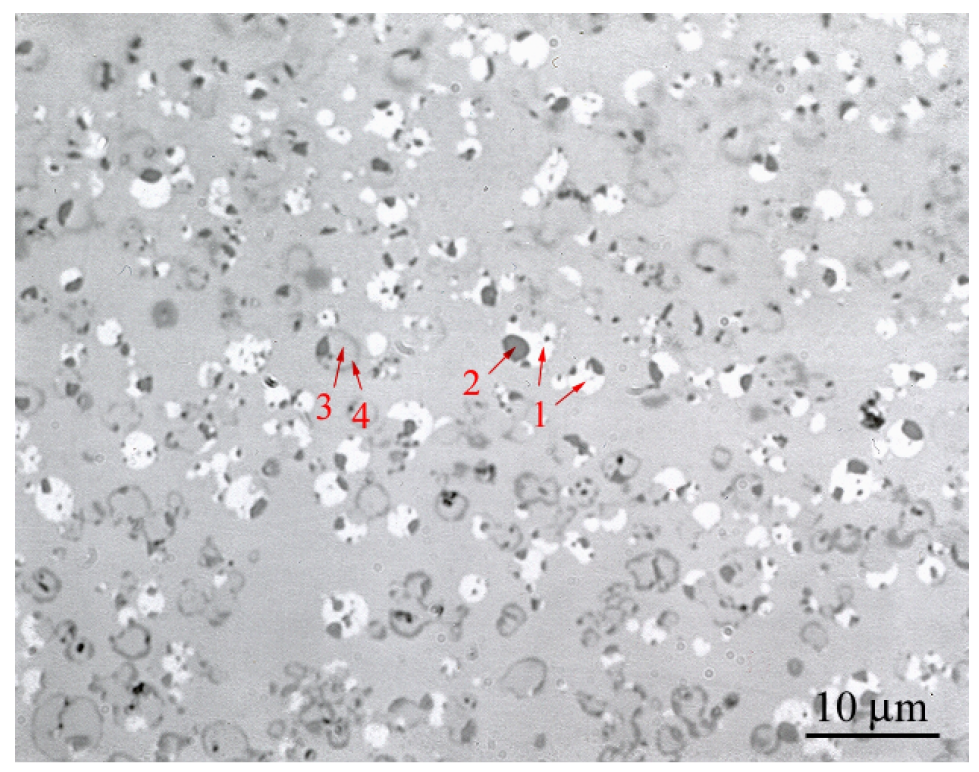

Figure 10b. Morphology of Ni-Al-Si coating held isothermally at $415^{\circ} \mathrm{C}$ for 24 hours. $1-$ unreacted Al-Si and 2,3,4 - intermetallics. 

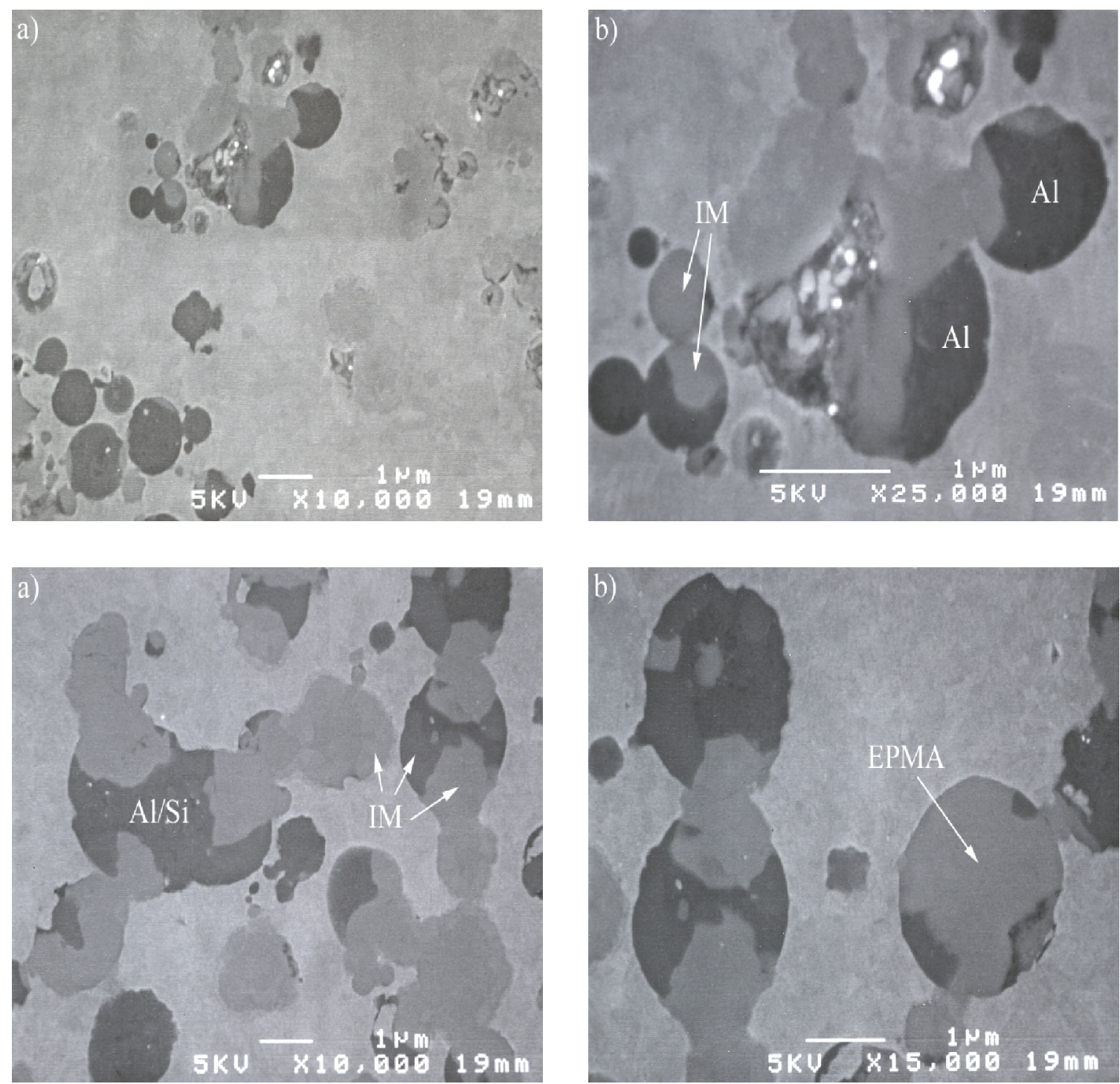

Figure 11. SEM photomicrographs of Ni-Al sample held at $415^{\circ} \mathrm{C}$ for 24 hours. Figure 12. High magnification view of Ni-Al-Si coating held at $415^{\circ} \mathrm{C}$ for 24 hours. (arrows - phases analyzed by EPMA) 
Electron probe microanalysis (EPMA) was conducted on the $415^{\circ} \mathrm{C}$, 24-hour samples to identify the phases present. Only the larger intermetallic phases could be analyzed due to the resolution (approximately one cubic micron) of the technique. Table II contains EPMA results for the binary Ni-Al coating. Based on the EPMA results, the major intermetallic phase was identified as $\beta \mathrm{NiAl}$. This phase corresponds to the dark gray intermetallic (phase "2") in Figure 10a. The composition of the matrix was also measured, as shown in Table II, and the Al content of the matrix was found to be very low at this diffusion temperature. EPMA was attempted on the concentric phases as well. The inner phase had a composition of 73.2 atomic $\% \mathrm{Al}$, which corresponds closely to $\mathrm{NiAl}_{3}$, while the outer "ring" may be $\mathrm{Ni}_{2} \mathrm{Al}_{3}$, although caution should be used in interpreting single EPMA measurements. In any case, the results show that the inner phase is a more Al-rich intermetallic, as expected for spherical diffusion couples between the Al particles and Ni matrix.

Table II. EPMA results for $\mathrm{Ni}-\mathrm{Al}$ annealed at $415^{\circ} \mathrm{C}$ for 24 hours.

\begin{tabular}{|c|c|c|}
\hline $\begin{array}{c}\text { Intermetallic Phase }- \\
\text { Measurment No. }\end{array}$ & Atomic $\% \mathrm{Ni}$ & Atomic $\% \mathrm{Al}$ \\
\hline 1 & 45.9 & 54.1 \\
\hline 2 & 44.8 & 55.2 \\
\hline 3 & 47.9 & 52.2 \\
\hline 4 & 44.5 & 55.5 \\
\hline 5 & 45.1 & 54.9 \\
\hline Matrix - & & \\
\hline Measurment No. & & 0.1 \\
\hline 1 & 99.9 & 0.7 \\
\hline 2 & 99.3 & 0.5 \\
\hline 3 & 99.5 & \\
\hline
\end{tabular}

Table III contains EPMA results for the ternary Ni-Al-Si, $415^{\circ} \mathrm{C}$ 24-hour sample. The major intermetallic phase (arrow in Figure $12 \mathrm{~b}$ ) was identified as $\beta \mathrm{NiAl}(\mathrm{Si})$ with measured $\mathrm{Si}$ 
contents from 1.3 to 3.9 atomic percent. The other intermetallic phases could not be positively identified by this technique because of their small size. The matrix composition of the Ni-Al-Si sample is also contained in Table III and, as in the binary Ni-Al sample, the matrix is very low in aluminum.

Table III. EPMA results for Ni-Al-Si annealed at $415^{\circ} \mathrm{C}$ for 24 hours.

\begin{tabular}{|c|c|c|c|}
\hline $\begin{array}{c}\text { Intermetallic }- \\
\text { Measurment No. }\end{array}$ & Atomic \% Ni & Atomic \% Al & Atomic \% Si \\
\hline 1 & 56.0 & 42.7 & 1.3 \\
\hline 2 & 44.4 & 51.9 & 3.7 \\
\hline 3 & 43.2 & 53.0 & 3.9 \\
\hline Matrix Meas. No. & & & 0.2 \\
\hline 1 & 99.0 & 0.8 & \\
\hline
\end{tabular}

The results for long-term diffusion at $415^{\circ} \mathrm{C}$ indicate that the particles behave as small, spherical diffusion couples with the nickel matrix. Intermetallic phases including NiAl, and possibly $\mathrm{NiAl}_{3}$ and $\mathrm{Ni}_{2} \mathrm{Al}_{3}$, form concentrically with Al-rich phases at the center. Some unreacted $\mathrm{Al}$ remains in the microstructure after 24 hours and the aluminum content in the $\mathrm{Ni}$ matrix is very low (Table III).

\section{NiAl Formation $\left(\sim 500-530^{\circ} \mathrm{C}\right)$}

If the composite coatings are continuously heated through the $400-450^{\circ} \mathrm{C}$ range (heating rate $10^{\circ} \mathrm{C} / \mathrm{min}$ ), without allowing time for diffusion, then a large fraction of the original $\mathrm{Al}$ particles will remain unreacted (metastable) in the Ni matrix. If heating is continued, however, an exothermic reaction is encountered as shown by the DTA data of Figure 9. The following 
section describes the morphology of DTA samples stopped within the reaction peak (partial DTA curve in Figure 9b) and immediately air cooled.

Figure 13 shows an LOM photomicrograph of a Ni-Al coating heated to $522^{\circ} \mathrm{C}$ and then cooled. The particles appear dark gray indicating an intermetallic phase (compare to light colored Al particles in Figures 1 and 2). An interesting feature of Figure 13 is a thin layer of unreacted $\mathrm{Al}$ particles at the coating/substrate interface, caused by the heat sink effect of the nickel substrate. EPMA results for the intermetallic phase and the Ni matrix are given in Table IV. The only intermetallic phase identified was NiAl with an average composition from three measurements of $51 \pm 3$ at. $\% \mathrm{Ni}$ and $49 \pm 3$ at. $\%$ Al. The EPMA measurements for the Ni-rich $\gamma$ matrix have a range of $\mathrm{Al}$ content from 0.7 to 3.2 atomic percent. During diffusion, the matrix will contain a concentration gradient of $\mathrm{Al}$ from regions near $\mathrm{Al}$ particles to regions in the center of the interparticle spaces. Therefore, the Al content measured will vary depending on the exact location of the electron probe. The results for Ni-Al-Si are shown in Table V for a partially reacted coating. The intermetallic phase in the Ni-Al-Si sample appears to be $\mathrm{NiAl}(\mathrm{Si})$. 


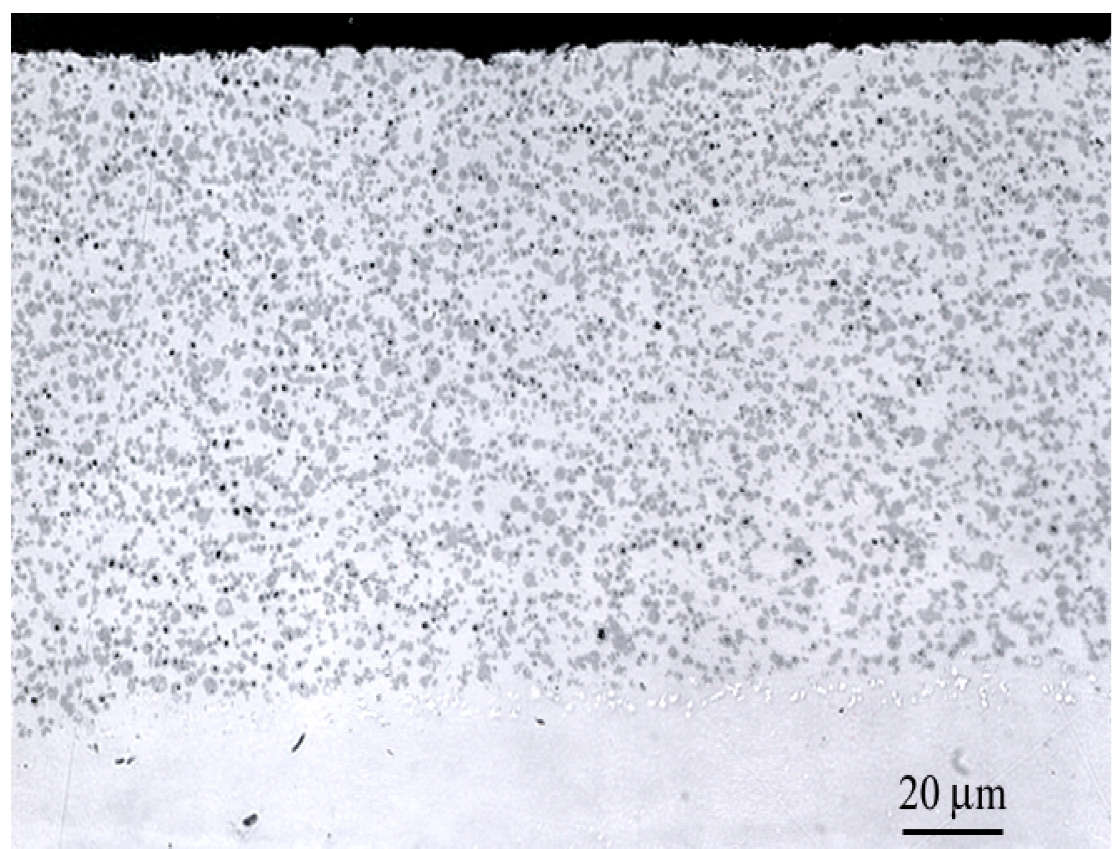

Figure 13. LOM photomicrograph of Ni-Al coating heated to $522^{\circ} \mathrm{C}$ and cooled.

Table IV. EPMA results for Ni-Al partially reacted at $522^{\circ} \mathrm{C}$.

\begin{tabular}{|c|c|c|}
\hline $\begin{array}{c}\text { Intermetallic Phase }- \\
\text { Measurement No. }\end{array}$ & Atomic \% Ni & Atomic \% Al \\
\hline 1 & 47.5 & 52.5 \\
\hline 2 & 52.2 & 47.8 \\
\hline 3 & 53.9 & 46.1 \\
\hline $\begin{array}{c}\text { Matrix }- \\
\text { Measurement No. }\end{array}$ & \\
\hline 1 & 96.9 & 3.1 \\
\hline 2 & 97.8 & 2.2 \\
\hline 3 & 99.3 & 0.7 \\
\hline
\end{tabular}


Table V. EPMA results for Ni-Al-Si partially reacted at $508^{\circ} \mathrm{C}$.

\begin{tabular}{|c|c|c|c|}
\hline & Atomic \% Ni & Atomic \% Al & Atomic \% Si \\
\hline Intermetallic & 48.2 & 44.8 & 7.0 \\
\hline & & & 0.2 \\
\hline Matrix & 99.3 & 0.5 & \\
\hline
\end{tabular}

The DTA and microstructural analyses indicate NiAl formation occurs during heat treatment. However, the final coating microstructure is $\gamma(\mathrm{Ni})+\mathrm{Ni}_{3} \mathrm{Al}$. Philpot et al. [10] showed significant diffusional reactions could take place both before and after the observed reaction peak(s). In addition, Nishimura and Liu [19,20] showed that $\mathrm{Ni}_{3} \mathrm{Al}$ formation proceeds through several steps from the aluminum side of the phase diagram toward $\mathrm{Ni}_{3} \mathrm{Al}$. In the present study, the formation of $\mathrm{NiAl}$ is also an intermediate step and, if heating is continued, the microstructure continues to transform by diffusion to the final $\gamma+\gamma^{\prime}$ morphology discussed below.

\section{High Temperature $\left(\sim 600-1000^{\circ} \mathrm{C}\right)$}

Immediately after the formation of $\mathrm{NiAl}$, the sample microstructure contains $\mathrm{NiAl}+\gamma(\mathrm{Ni})$ matrix. If heating is continued, or if the sample is held isothermally at high temperature, interdiffusion of $\mathrm{Ni}$ and $\mathrm{Al}$ continues and $\mathrm{NiAl}$ begins to dissolve. As diffusion continues further, $\mathrm{Ni}_{3} \mathrm{Al}$ is formed between $\mathrm{NiAl}$ and the $\gamma(\mathrm{Ni})$ matrix. However, no DTA peak was found for $\mathrm{Ni}_{3} \mathrm{Al}$ formation. The absence of a peak may be due to the small amount of $\mathrm{Ni}_{3} \mathrm{Al}$ formation $\left(\mathrm{Ni}_{3} \mathrm{Al}\right.$ forms only at the interface between $\mathrm{NiAl}$ particles and $\left.\gamma\right)$ and/or the lower heat of reaction of the $\gamma^{\prime} \mathrm{Ni}_{3} \mathrm{Al}$ phase. Also, the number of peaks found has been shown to depend on heating rate (heating rate was $10^{\circ} \mathrm{C} / \mathrm{min}$ in this study). Philpot et al. [10] found two reaction peaks for samples with a slow heating rate $\left(1^{\circ} \mathrm{C} / \mathrm{min}\right)$ and only one peak for samples with a faster heating 
rate $\left(5^{\circ} \mathrm{C} / \mathrm{min}\right)$. The final microstructure (after heating to the final temperature) was the same in both cases. Based on these studies, the number of peaks may depend on heating rate, but the exact relationship is still unknown.

The diffusion process continues until the NiAl phase eventually disappears. Depending on the composition of the $\mathrm{Ni}$ matrix, i.e. if it is not yet saturated in $\mathrm{Al}$, the $\mathrm{Ni}_{3} \mathrm{Al}$ phase may also begin to dissolve. The sample microstructure finally reaches equilibrium when the $\gamma$ phase reaches its solubility limit for $\mathrm{Al}$. The initial composition of the Ni-Al composite and the diffusion temperature will determine the amounts of $\gamma$ and $\gamma^{\prime}$ present in the final microstructure. The final microstructure was described above for general coating heat treatment.

\section{DISCUSSION}

\section{AS-DEPOSITED COATINGS}

With regard to powder bath loading, it has been found that an increase in particle content of the bath produces an increase of particles in the coatings [1,12] (Figure 3). However, the effect eventually levels out at high bath content and further bath increases do not produce appreciable increases in coating particle content. The Al-12Si particles showed a higher maximum particle content in the coatings than pure Al. This difference may be caused by different surface charges developed on the particles within the plating bath. Differences in codeposition behavior have been observed previously during codeposition of ceramic vs. metallic particles [7]. For small ceramic particles $\left(\mathrm{Al}_{2} \mathrm{O}_{3}\right)$, a maximum of about 35 volume percent particles in a nickel matrix was found for particle bath loading of $300 \mathrm{~g} / \mathrm{l}$ [7]. For metallic Al particles in a nickel matrix, similar bath loadings result in coatings with about 20 volume percent $\mathrm{Al}$ particles. It is suspected that the difference in codeposition behavior is 
caused by differences in particles size (smaller ceramic powders were used) and differences in surface charge developed on the two types of particles while dispersed in the electrodeposition bath. A similar effect may be occurring for Al vs. Al-12Si particles in the present work.

\section{PHASE FORMATION}

The EPMA and morphological analyses show that the DTA peak is produced by $\beta \mathrm{NiAl}$ formation. Immediately after the reaction, the microstructure consists of $\beta \mathrm{NiAl}+\gamma(\mathrm{Ni})$. The reaction between $\mathrm{Al}$ particles and the Ni matrix can be written as:

$$
\mathrm{Ni}+\mathrm{Al} \rightarrow \mathrm{NiAl}
$$

The reaction is highly exothermic with heat of formation (reaction enthalpy) of $-58.8 \mathrm{~kJ} / \mathrm{mol}$ [21].

The reaction of particles during heating of Ni-Al intermetallic coatings is a small-scale (occurring over a range of a few microns) variant of the bulk reaction synthesis process. In bulk reaction synthesis, typical particle sizes are much larger and the reaction occurs over a much larger spatial range. Several studies have been performed on the formation of bulk intermetallics from $\mathrm{Ni}$ and $\mathrm{Al}$ powders [10,11,22-27]. Bulk nickel-aluminum intermetallics can also be formed by the infiltration of liquid aluminum into a Ni powder preform [26,27]. Reaction synthesis involves the formation of a compound through an exothermic reaction until the reactants are consumed. Intermetallic formation with this technique can be accomplished in two modes [11]: self-propagating and thermal explosion. In the self-propagating mode, the reactants are ignited at one end of a powder compact and the reaction propagates through the compact in the form of a 
combustion front. In the thermal explosion mode, the powder mixture is heated in a furnace until the onset of reaction between the powders $[10,11]$ throughout the sample. The reaction of the $\mathrm{Ni}$ matrix and $\mathrm{Al}$ particles in an EMMC coating probably occurs by the thermal explosion mode although it may also be possible to ignite one end of the coating to induce the self-propagating mode of reaction synthesis. It has been reported [28] that the final density of reactively sintered materials very often does not reach its theoretical density and can be as low as $60 \%$ of its theoretical value. Vast outgassing is often observed at the beginning of the exothermic reaction. It is especially true when uncontrolled reaction takes place and produces high reaction temperature and subsequent trapped gas in the partially densified sample.

Philpot et al. [10] studied reaction synthesis of $\mathrm{Ni}-\mathrm{Al}$ powder compacts over a range of $\mathrm{Al}$ compositions and heating rates. Intermetallic phase formation occurred between 500 and $625^{\circ} \mathrm{C}$, depending on heating rate, $\mathrm{Al}$ content, and particle size ratio. This range of reaction temperature corresponds well to the current study of Ni-Al composite coatings. Misiolek and German [24] found the $\mathrm{Ni}_{3} \mathrm{Al}$ reaction occurred at about $600^{\circ} \mathrm{C}$ for $70 \%$ dense compacts heated at $10^{\circ} \mathrm{C} / \mathrm{min}$. These studies show that aluminide reactions are initiated in the solid state, below the lowest melting point of the Ni-Al system (see Figure 4). Based on thermocouple measurements, Philpot et al. [10] showed significant temperature increases (as much as $800^{\circ} \mathrm{C}$ ) were caused by the exothermic reactions. Therefore, although the reaction begins in the solid state, Al melting occurs and at least part of the intermetallic formation takes place as a liquid/solid reaction. Indeed, all of the studies mentioned above showed that liquid formation takes place due to the heat generated during exothermic reaction. It is suspected that melting also occurs in the coating samples in the present research. However, since the reaction is occurring on a very small scale 
between isolated particle/matrix couples, it is difficult to find evidence for melting in the microstructure.

\section{PORE FORMATION}

In bulk reaction synthesis, porosity is always found in the resultant microstructure [11, $22,24]$ unless compression is applied during the propagation stage of the reaction [24,25]. A second method to reduce porosity is to react at lower temperatures, thereby slowing down the reaction. In composite coatings, it appears that low temperature holds and diffusional transformation to several intermetallics results in a lower porosity content (Figures 10 to 12), especially for Ni-Al-Si samples. However, for oxidation resistance (the important coating property for industrial application), complete conversion of the microstructure to $\gamma+\gamma^{\prime}$ is desired, which may not be feasible at low temperatures. The porosity content can also be reduced if a continuous liquid $\mathrm{Al}$ network is produced [24]. The liquid reduces the porosity in the compact through capillary forces. This situation is characteristic for relatively low Ni to Al particle size ratios. Small Al particles can provide a network of particles in physical contact for any given chemical composition. However, if the Al particles are isolated (as in composite coatings), local densification will occur without a continuous liquid network, resulting in pore formation as discussed below.

The pores throughout the microstructure in the Ni-Al EMMC coatings are probably formed due to local density changes as the $\mathrm{Al}$ particles and $\mathrm{Ni}$ matrix transform to intermetallic phases. Since the Ni matrix is already fully dense, and no external pressure is applied, the porosity forms as a direct result of intermetallic formation. The density of $\mathrm{Al}, \mathrm{NiAl}, \mathrm{Ni}_{3} \mathrm{Al}$ and $\mathrm{Ni}$ are $2.7,5.86,7.50$, and $8.9 \mathrm{~g} / \mathrm{cm}^{3}$, respectively [29,30]. Calculation shows that a composite of 
25 atomic $\% \mathrm{Al}$ and 75 atomic $\% \mathrm{Ni}$ that fully transforms to $\mathrm{Ni}_{3} \mathrm{Al}$ will have $9 \%$ resultant porosity due to density changes. The porosity of Ni-Al EMMC annealed coatings measured by QIA was about $8 \%$. In addition, some pore formation may also be accounted for by the loss of Al due to vaporization after melting and/or by the Kirkendall effect. Kirkendall void formation occurs in the $\mathrm{Ni}-\mathrm{Al}$ system, producing voids near the reaction interface during diffusion $[31,32]$. However, the major pore formation mechanism is believed to be local densification based on the overall pore morphology within the coatings. Previous research conducted by Misiolek et al. $[28,33,34]$ showed a potential solution to the pore formation problem by applying pressure during reactive sintering. Successful experiments were conducted for NiAl and NiAl/ $/ \mathrm{TiB}_{2}$ composites as well as for $\mathrm{TiC}$ and $\mathrm{TiB}_{2}$ ceramic materials.

\section{SUMMARY OF COATING MORPHOLOGICAL DEVELOPMENT}

To summarize the morphological development during heat treatment of $\mathrm{Ni}-\mathrm{Al}$ based composite coatings, a schematic model is presented in Figure 14. The diagram shows three regimes corresponding to low temperature, intermediate temperature (NiAl formation), and high temperature behavior. During heating through $400-450^{\circ} \mathrm{C}$, a majority of $\mathrm{Al}$ particles remain unreacted. If held for long times, however, the $\mathrm{Al}$ particles and $\mathrm{Ni}$ matrix behave as small diffusion couples with concentric formation of Al-rich phases and NiAl, with unreacted Al possibly remaining at the center. In Ni-Al-Si samples, the microstructure is complex and several intermetallics are formed. As heating is continued, the formation of NiAl occurs by an exothermic reaction between the metastable $\mathrm{Al}$ particles and the Ni matrix. (In addition, 
throughout the temperature profile, the amount of Al gradually increases in the $\gamma$ phase matrix.) When the NiAl reaction is complete, the microstructure consists of $\mathrm{NiAl}+\gamma(\mathrm{Ni})$. At higher temperatures and longer times, diffusion continues and $\mathrm{Ni}_{3} \mathrm{Al}$ is formed between $\mathrm{NiAl}$ and $\gamma$ until the NiAl phase is eventually consumed. The final annealed coating contains a two-phase mixture of $\gamma+\gamma$. It is believed that pore formation occurs due to local densification because of the higher densities of the intermetallic phases.

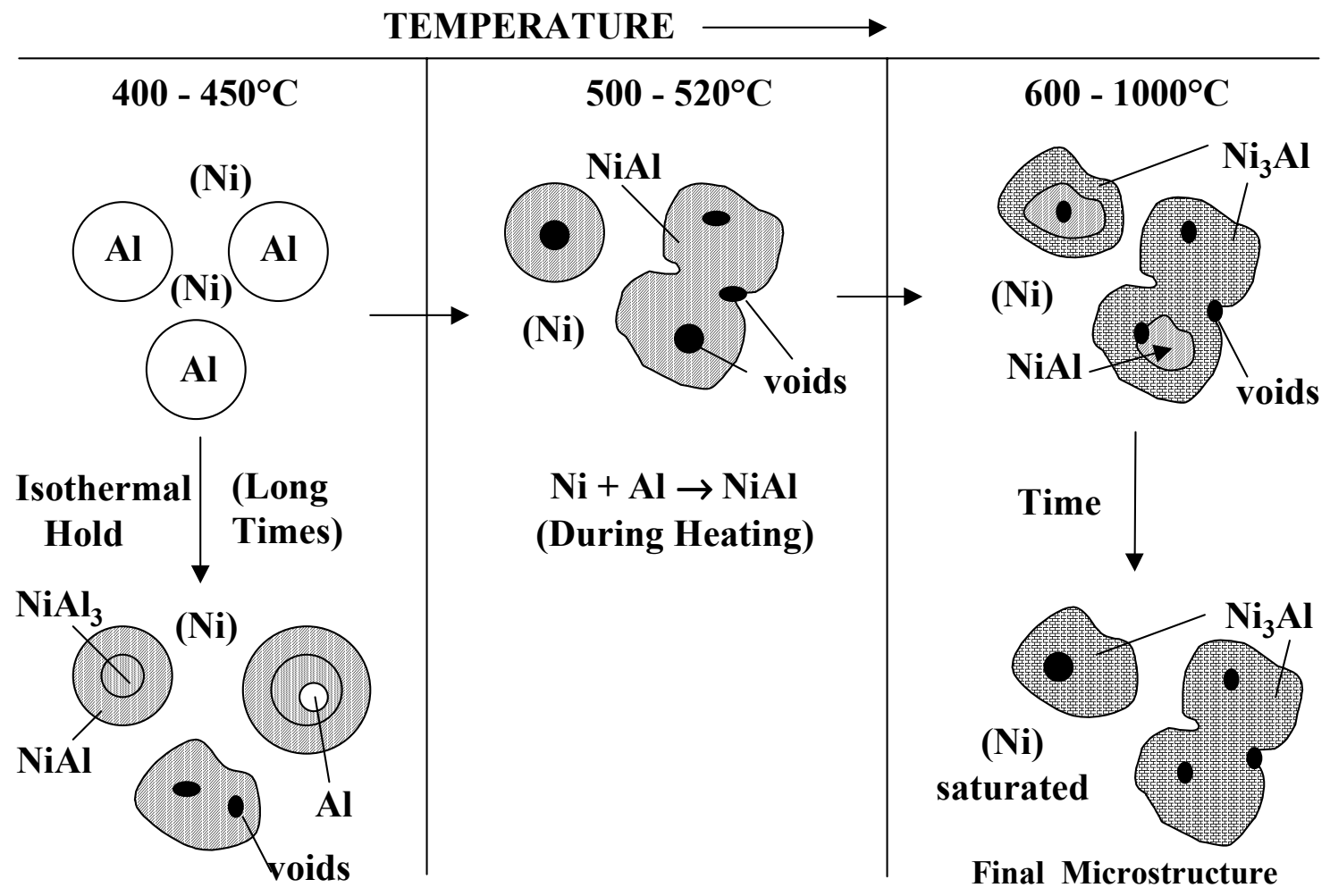

Figure 14. Schematic model of microstructural development during heat treatment of Ni-Al type composite coatings. 


\section{CONCLUSIONS}

1. The amount of particles codeposited into a nickel matrix increases as the amount of particles in the bath is increased. A maximum amount of codeposited particles is obtained at bath loading of $300 \mathrm{~g} / \mathrm{l}$ or higher. Codeposition of $\mathrm{Al}$ particles into a nickel matrix produces coatings with a uniform distribution of particles and up to about 20 vol. \% particles for bath loading above $300 \mathrm{~g} / 1$ and deposition current density of $4.5 \mathrm{~A} / \mathrm{dm}^{2}$. For codeposition of Al12Si particles, a maximum of about 30 vol. \% particles is achieved at powder bath loading above $300 \mathrm{~g} / \mathrm{l}$.

2. Heat treatment at low temperatures $\left(400-450^{\circ} \mathrm{C}\right)$ results in diffusional reaction between the Al particles and nickel matrix to produce a range of $\mathrm{Ni}-\mathrm{Al}$ intermetallics. Intermetallic phases form concentrically around the original $\mathrm{Al}$ particles or at the original $\mathrm{Al} / \mathrm{Ni}$ interfaces. Phases form that bridge several neighboring particles indicating overlapping diffusion fields within the coating. Some unreacted Al particles remain after long-time exposure at low temperatures.

3. During heating, $\beta \mathrm{NiAl}$ is formed at about $520^{\circ} \mathrm{C}$ by a rapid, exothermal reaction between the Al particles and $\mathrm{Ni}$ matrix. Immediately after the reaction, the coating microstructure consists of $\beta \mathrm{NiAl}$ particles in a Ni matrix with some $\mathrm{Al}$ in solution.

4. At higher temperatures (or longer times), the $\gamma^{\prime} \mathrm{Ni}_{3} \mathrm{Al}$ phase is formed between $\mathrm{NiAl}$ and $\gamma \mathrm{Ni}(\mathrm{Al})$. The final coating morphology consists of blocks of $\gamma^{\prime} \mathrm{Ni}_{3} \mathrm{Al}$ in a saturated $\mathrm{Ni}$ solid solution matrix. Small pores within the coating are likely formed by local densification during intermetallic formation. 


\section{ACKNOWLEDGEMENTS}

The expert metallographic assistance of A.O. Benscoter is greatly appreciated. The SEM and EPMA guidance of D. Ackland and K. Repa was essential to the completion of this project. This work was performed under the DOE, Federal Energy Technology Center, Innovative Concepts Program. Thanks also to Dr. C.V. Robino (Sandia) for review of the manuscript. Sandia is a multiprogram laboratory operated by Sandia Corporation, a Lockheed Martin Company, for the United States Department of Energy under Contract DE-AC04-94AL85000. 


\section{REFERENCES}

1. R. Bazzard and P.J. Boden: Trans. Inst. Metal Finishing, 1972, vol. 50, pp. 63-69.

2. J. Foster, B.P. Cameron, and J.A. Carew: Trans. Inst. Metal Finishing, 1985, vol. 63, pp. 115-119.

3. F.J. Honey, E.C. Kedward, and V. Wride: J. Vacuum Sci. and Tech., 1986, vol. 4, no. 6.

4. T. Osaka, I. Koiwa, M. Usuda, K. Arai, and I. Saito: J. Electrochem. Soc., 1989, vol. 136, no. 4, pp. 1124-1128.

5. M. Izaki, M. Fukusumi, H. Enomoto, T. Omi, and Y. Nakayama: J. Japan Inst. Met., 1993, vol. 57, no. 2, pp. 182-189.

6. D.F. Susan, A.R. Marder, and K. Barmak: Thin Solid Films, 1997, vol. 307, pp. 133-140.

7. K. Barmak, S.W. Banovic, C.M. Petronis, D.F. Susan, and A.R. Marder: J. of Microscopy, 1997, vol. 185 , pt. 2, pp. 265-274.

8. M.P. Brady, B.A. Pint, P.F. Tortorelli, I.G. Wright, and R.J. Hanrahan: Chapter 6 in Corrosion and Environmental Degradation of Materials, Vol. 19B, Materials Science and Technology, M. Schutze (volume editor), Wiley-VCH, Weinheim, Germany, in press.

9. J. Doychak: Intermetallic Compounds: Vol. 1, Principles, eds. J.H. Westbrook and R.L. Fleischer, John Wiley \& Sons Ltd., New York, 1995.

10. K.A. Philpot, Z.A. Munir, and J.B. Holt: J. Mater. Sci., 1987, vol. 22, pp. 159-169.

11. A. Varma and J.-P. Lebrat: Chem. Eng. Sci., 1992, vol. 47 no. 9-11, pp. 2179-2194.

12. N. Guglielmi: J. Electrochem.. Soc., 1972, vol. 119, no. 8, pp. 1009-1012.

13. R.A.F. Hammond: Met. Finishing J., June 1970, pp. 169-176.

14. American Society for Metals: Metals Handbook, $9^{\text {th }}$ Ed., vol. 5, 1979, pp. 199-218.

15. S.W. Banovic, K. Barmak, and A.R. Marder: J. Mater. Sci., 1998, vol. 33, pp. 639-645. 
16. G. Beuers, C. Batzner, and H.L. Lukas: Ternary Alloys, vol. 7, eds. G. Petzow and G. Effenburg, VCH Publishers, New York, 1993.

17. ASM Handbook, Vol. 3, $10^{\text {th }}$ Ed., H. Baker (editor), American Society for Materials International, Materials Park, OH, 1992.

18. W.Z. Misiolek and R.M. German: 1990 Advances in Powder Metallurgy, vol. 2, MPIF, Princeton, NJ, 1990, pp. 161-172.

19. C. Nishimura and C.T. Liu: Scripta Metall. Mater., 1992, vol. 26, pp. 381-385.

20. C. Nishimura and C.T. Liu: Acta Metall. Mater., 1993, vol. 41, no. 1, pp. 113-120.

21. R. Hultgren: Selected Values of Thermodynamic Properties of Metals and Alloys, ASM, Metals Park, OH, 1973, pg. 191.

22. A. Bose, B. Moore, R.M. German, and N.S. Stoloff: JOM, Sept. 1988, pp. 14-17.

23. J.B. Holt and S.D. Dunmead: Ann. Rev. Mater. Sci., 1991, vol. 21, pp. 305-334.

24. W.Z. Misiolek and R.M. German: Mat. Sci. and Eng. A, 1991, vol. A144, pp. 1-10.

25. D. Alman: J. Mater. Sci. Letters, 1994, vol. 13, pp. 483-486.

26. D.C. Dunand, J.L. Sommer, and A. Mortensen: Met. Trans. A, 1993, vol. 24A, pp. 21612170.

27. D.C. Dunand: J. Mater. Sci., 1994, vol. 29, pp. 4056-4060.

28. W.Z. Misiolek, N.D. Sopchak, and R.M. German: Processing and Fabrication of Advanced Materials for High Temperature Applications, eds. V.A. Ravi and T.S. Srivatsan, TMS, Warrendale, PA, 1992, pp. 187-192.

29. American Society for Materials: Metals Handbook, Desk Edition, ASM, Materials Park, OH, 1985. 
30. J.H. Westbrook and R.L. Fleischer (eds.): Intermetallic Compounds: Principles and Applications, Wiley, New York, 1995.

31. M. Watanabe, Z. Horita, D.J. Smith, M.R. McCartney, T. Sano, and M. Nemoto: Defect and Diffusion Forum, 1993, vol. 95-98, pg. 587.

32. M.M.P. Jansenn and G.D. Rieck: Trans. AIME, 1967, vol. 239, pp. 1372-1385.

33. W.Z. Misiolek: Processing and Fabrication of Advanced Materials for High Temperature Applications-II, eds. V.A. Ravi and T.S. Srivatsan, TMS, Warrendale, PA, 1993, pp. 279289.

34. W.Z. Misiolek, T.D. Schurman, and N.D. Sopchak: Advances in Powder Metallurgy and Particulate Materials-1992, vol. 9, MPIF, Princeton, NJ, 1992, pp. 411-422. 
Ni-Al COMPOSITE COATINGS:

DIFFUSION ANALYSIS AND COATING LIFETIME ESTIMATION

\author{
${ }^{\mathrm{a}}$ D.F. Susan and ${ }^{\mathrm{b}}$ A.R. Marder \\ ${ }^{a}$ Sandia National Laboratory, Albuquerque, NM \\ ${ }^{\mathrm{b}}$ Lehigh University, Bethlehem, PA
}

\begin{abstract}
The interdiffusion of Ni matrix/Al particle composite coatings and nickel substrates was studied using electron probe microanalysis (EPMA) and a one-dimensional diffusion model. The initial coating microstructure was a two-phase mixture of $\gamma(\mathrm{Ni})$ and $\gamma^{\prime}\left(\mathrm{Ni}_{3} \mathrm{Al}\right)$. The coating/substrate assemblies were aged at 800 to $1100^{\circ} \mathrm{C}$ for times up to 2000 hours. It was found that aluminum losses to the substrate are significant at $1000^{\circ} \mathrm{C}$ and above. The experimental results for the diffusion of $\mathrm{Al}$ into the substrate were compared to model predictions based on a diffusion equation for a finite layer on an infinite substrate. Using combined experimental and model results, the effects of temperature and coating thickness were determined and a rationale was developed for coating lifetime prediction.
\end{abstract}




\title{
OXIDATION OF Ni-AI BASED \\ ELECTRODEPOSITED COMPOSITE COATINGS \\ I: OXIDATION KINETICS AND MORPHOLOGY AT $800^{\circ} \mathrm{C}$
}

\author{
D.F. Susan ${ }^{\mathrm{a}}$ and A.R. Marder ${ }^{\mathrm{b}}$ \\ ${ }^{a}$ Sandia National Laboratory, Albuquerque, NM \\ ${ }^{\mathrm{b}}$ Materials Science and Engineering Department, \\ Lehigh University, Bethlehem, PA
}

\begin{abstract}
The oxidation of nickel-matrix /aluminum-particle composite coatings was studied using thermogravimetric (TG) analysis in air at $800^{\circ} \mathrm{C}$ for up to 100 hours. Long-term oxidation behavior was investigated with furnace exposures up to 2000 hours. The coatings were applied to nickel substrates by the composite electrodeposition technique and vacuum heat treated for three hours at $825^{\circ} \mathrm{C}$ prior to oxidation testing. The heat-treated coatings contained a two-phase $\gamma(\mathrm{Ni})+\gamma^{\prime}\left(\mathrm{Ni}_{3} \mathrm{Al}\right)$ microstructure and the overall coating composition was approximately $7 \mathrm{wt} . \%$ Al. Also examined were uncoated nickel substrates and bulk Ni-Al alloys containing 6.2, 9.0, and 14 wt. \% Al. For all samples, mass gain kinetics were obtained from TG experiments and furnace exposures and the composition and morphology of the oxidation products were examined using optical microscopy, scanning electron microscopy (SEM), electron probe microanalysis (EPMA), and x-ray diffraction (XRD). An outer NiO layer and an inner $\gamma-\mathrm{Al}_{2} \mathrm{O}_{3}$ layer were formed on the composite coating surface. The addition of a small amount of Si (about 1-2 at.\%) was found to have little effect on Ni-Al composite coating oxidation behavior. The NiAl coatings behave similarly to bulk $\gamma+\gamma^{\prime}\left(\mathrm{Ni}_{3} \mathrm{Al}\right)$ or single phase $\gamma^{\prime}\left(\mathrm{Ni}_{3} \mathrm{Al}\right)$. In addition, at lower temperatures such as $800^{\circ} \mathrm{C}$, the coatings benefit from a small grain size that enhances $\mathrm{Al}$ diffusion to the surface to form the protective alumina layer. Based on oxidation kinetics and morphology, a critical Al content of about 6 wt. \% was found, below which internal oxidation attack and higher oxidation mass gains were observed.
\end{abstract}




\title{
OXIDATION OF Ni-AI BASED \\ ELECTRODEPOSITED COMPOSITE COATINGS \\ II: OXIDATION KINETICS AND MORPHOLOGY AT $1000^{\circ} \mathrm{C}$
}

\author{
D.F. Susan ${ }^{\mathrm{a}}$ and A.R. Marder ${ }^{\mathrm{b}}$ \\ ${ }^{a}$ Sandia National Laboratory, Albuquerque, NM \\ ${ }^{\mathrm{b}}$ Materials Science and Engineering Department, \\ Lehigh University, Bethlehem, PA
}

\begin{abstract}
The oxidation behavior of nickel-matrix/aluminum-particle composite coatings was studied using thermogravimetric (TG) analysis and long-term furnace exposure in air at $1000^{\circ} \mathrm{C}$. The coatings were applied by the composite electrodeposition technique and vacuum heat treated for three hours at $825^{\circ} \mathrm{C}$ prior to oxidation testing. The heat-treated coatings consisted of a twophase mixture of $\gamma(\mathrm{Ni})+\gamma^{\prime}\left(\mathrm{Ni}_{3} \mathrm{Al}\right)$. During short-term exposure at $1000^{\circ} \mathrm{C}$, a thin $\alpha-\mathrm{Al}_{2} \mathrm{O}_{3}$ layer developed below a matrix of spinel $\mathrm{NiAl}_{2} \mathrm{O}_{4}$, with $\theta-\mathrm{Al}_{2} \mathrm{O}_{3}$ needles at the outer oxide surface. After 100 hours of oxidation, remnants of $\theta-\mathrm{Al}_{2} \mathrm{O}_{3}$ are present with spinel at the surface and an inner layer of $\alpha-\mathrm{Al}_{2} \mathrm{O}_{3}$. After 1000-2000 hours, a relatively thick layer of $\alpha-\mathrm{Al}_{2} \mathrm{O}_{3}$ is found below a thin outer spinel layer. Oxidation kinetics are controlled by the slow growth of the inner $\mathrm{Al}_{2} \mathrm{O}_{3}$ layer at short-term and intermediate exposures. At long times, an increase in mass gain is found due to oxidation at the coating/substrate interface and enhanced scale formation possibly in areas of reduced $\mathrm{Al}$ content. Ternary $\mathrm{Si}$ additions to $\mathrm{Ni}-\mathrm{Al}$ composite coatings were found to have little effect on oxidation performance. Comparison of coatings with bulk Ni-Al alloys showed that low $\mathrm{Al} \gamma$-alloys exhibit a healing $\mathrm{Al}_{2} \mathrm{O}_{3}$ layer after transient Ni-rich oxide growth. Higher $\mathrm{Al}$ alloys display $\mathrm{Al}_{2} \mathrm{O}_{3}$-controlled kinetics with low mass gain during TG analysis.
\end{abstract}

